Research Article

\title{
Three-Dimensional Finite Difference Analysis on the Ground-Sequential Tunneling-Superstructure Interaction
}

\author{
Ali Lakirouhani ID $^{1}{ }^{1}$ Reyhaneh Jafari, ${ }^{2}$ and Hadi Hasanzadehshooiili (iD ${ }^{3}$ \\ ${ }^{1}$ Department of Civil Engineering, Faculty of Engineering, University of Zanjan, Zanjan, Iran \\ ${ }^{2}$ Department of Civil Engineering, Faculty of Engineering, University of Zanjan, Zanjan, Iran \\ ${ }^{3}$ Department of Civil and Water Engineering, Laval University, Quebec, Canada \\ Correspondence should be addressed to Ali Lakirouhani; rou001@znu.ac.ir
}

Received 9 April 2021; Revised 20 May 2021; Accepted 1 June 2021; Published 14 June 2021

Academic Editor: Chunshun Zhang

Copyright (c) 2021 Ali Lakirouhani et al. This is an open access article distributed under the Creative Commons Attribution License, which permits unrestricted use, distribution, and reproduction in any medium, provided the original work is properly cited.

\begin{abstract}
In this paper, a three-dimensional finite difference analysis is presented to investigate the interactive effects of sequential tunneling and the superstructure on the settlement profile of the ground. To simulate the practical sequential tunneling procedure, tunnel excavation is conducted in a step-by-step framework; tunnel excavation starts from the beginning of the model and is updated in a continuous manner, and the installation of the tunnel support system is done with a delay step compared to tunnel excavation. The numerical modeling accuracy is validated using the available analytical and numerical solutions for both two-dimensional and three-dimensional simplified cases. The well-validated modeling procedure is adopted to investigate effects of tunnel diameter, depth of tunneling, and number of superstructure stories on the profile of occurring settlements. Two cases of free-field and threedimensional superstructural modeling are compared with regard to the effect of tunneling. In addition, the effect of tunneling advancement on the generation of excess structural forces and moments are studied as another important factor in the soiltunneling-superstructure interaction problem. It is observed that, in the free-field case, with advancing the tunnel face, the longitudinal settlement profiles approach the steady-state condition and the maximum ground settlement tends to converge to a specific value, whereas as the tunnel passes under a structure, the settlement increases steadily as the tunnel progresses. There is a direct relationship between the depth and diameter of the tunnel and the settlement. In addition, the effect of the number of superstructure stories on the maximum settlement is more considerable compared to the free-field condition. According to the results, when the tunnel passes under 8 -story and 12-story structures, the maximum settlement increases by $40 \%$ and $70 \%$, respectively, compared to the free-field condition. It is also shown that tunneling-induced settlements result in the regeneration of structural forces.
\end{abstract}

\section{Introduction}

Due to the occurrence of settlements and settlement-induced displacements in surface structures, excavating tunnels in urban areas has always been of a great importance. Besides, structures constructed on the ground may be affected by the advancements in the tunneling in terms of displacements, drifts, and excess internal and structural forces/moments. This interactive nature makes it a coupled interaction problem, in which not paying enough and proper consideration to its modeling can be conducive to severe and intolerable consequences. Ground-tunneling-superstructure interaction problem can be analyzed from two different aspects. In the first approach, effects of the superstructure on the tunneling-induced displacements and stress fields are evaluated, while the second one deals with the vulnerability of superstructures against the displacements and stresses that emerged from the tunneling. In this regard, proper and accurate design of tunneling projects needs an in-depth understanding of this interaction nature. In recent years, such an investigation has been carried out based on empirical [1, 2], analytical [3], and numerical [4-10] methods. Among these methods, numerical techniques with the ability to model the more complicated problems (in forms of 
geometry, stress field, material property, etc.) have gained more attention. Mroueh and Shahrour showed that it is essential to adopt a three-dimensional modeling approach, which considers simultaneous effects of tunneling and superstructure. It was due to three-dimensional nature of the tunnel excavation and the nonlinear behavior of the soil [11]. In some other numerical investigations, to decrease the calculation time and efforts, the superstructure was assumed to be an elastic beam/plate with flexural and bending stiffness equal to the corresponding stiffness of the original superstructure [12-16]. Displacements and settlements that occurred were then assessed with advancing the tunnel face. Some researchers addressed low modeling accuracies and not presenting structural damages as shortcomings available in this approach. Despite those researchers, other studies showed that, with calibrating simplified numerical models (in the form of simplified superstructure) with the field cases, there can be more accurate numerical results $[17,18]$. But there was not still a general agreement in view of the simplified or detailed superstructural modeling. A need for properly characterizing the model using real field cases, not assuring its suitability for modeling more complicated cases and a need for the structural vulnerability analysis were the main reasons that three-dimensional modeling of the superstructure was further developed in recent years. Dias and Kastner conducted a case study on the effects of the superstructure (in the form of a structural frame) on the tunneling-induced ground settlements. They presented a comparison between the obtained results with the observations from a 6-story building located on the line 2 of Cairo metro. Compared to the results obtained from the field, their transverse settlement profile was wider, and the maximum settlement value was increased in the vicinity of the superstructure. Also, internal structural forces were affected by the tunneling operations [19]. Mroueh and Shahrour studied effects of the weight and the stiffness of a multistory frame on the transverse settlement profile and the internal structural forces using the three-dimensional modeling. As the first approach, they calculated the tunneling-induced settlements for the free-field state and as the next solution step, and they exerted the calculated settlement values to the superstructure. The second approach was a more accurate one, in which the tunnel advancement and the effect of the superstructure were considered simultaneously. It was concluded that the simplified model overestimates internal structural forces and moments as it neglects the stiffness of the superstructure in the calculation of settlements. They also investigated effect of the weight of the superstructure and found that not considering the structural weight will result in higher internal structural forces compared to the reality [11]. Jenck and Dias three-dimensionally studied the tunneling problem considering a structural frame as the superstructure (using columns and slabs elements, founded on a raft); evaluating effects of the weight and the stiffness of the structure on the settlement profiles, they found that the stiffness of the structure plays an important role in the modeling accuracy. They showed that the transverse settlement profile of the free field and the model with the consideration of the superstructure follow a relatively similar behavior [20]. Maleki et al. modeled a tunnel and the superstructure in a decoupled manner and did not take the simultaneous effects of tunneling and superstructure into consideration in their three-dimensional models. To model the superstructure, they analyzed two cases of an elastic plate as the foundation and the three-dimensional geometry of the superstructure. Results obtained from the three-dimensional geometry for the superstructure were more acceptable. Although values of the settlement obtained from two approaches were different, there were still common trends in the settlement profiles for both cases. Observed differences were believed to be attributed to the uniform distribution of the weight of the structure in the plate model compared to the dead column loads in the three-dimensional model of the superstructure [21]. What has not yet been considered in the earlier studies is the sensitivity of the settlement profiles to the size of the studied numerical model. Among the conducted studies, there is not a common agreement on the selection of the proper model sizes. As a matter of fact, the size of the numerical model should be adopted in a way to avoid the boundary effects on the results. Most researchers selected $6 D$ and $3 D$ values, respectively, for the minimum distance between the center of the tunnel and the vertical boundaries and the minimum distance between the center of the tunnel and the bottom boundary ( $D$ represents the tunnel diameter). Franzius studied an excavation length of more than 21 times of the tunnel diameter in his threedimensional investigation and the distance between the last tunnel face and the vertical side boundary was selected to be 11.5 times of the tunnel's diameter. Focusing on the longitudinal settlement profiles, it was observed that, with advancing tunnel face, steady-state settlement situation was not satisfied, emphasizing that the size of the model affects results [22]. Franzius et al. investigated the effect of the model size on the settlement and suggested that, to minimize the boundary effect, there should be at least a distance from the first excavation facing to the vertical side boundary equal to the 13 times of the tunnel diameter. But there was not still a steady-state situation in their longitudinal settlement profiles [23]. Some other researchers introduced $(H+4 D)$, $(H+3 D)$, and $(3 H)$, respectively, as the minimum required height, length, and width of the model, where $H$ and $D$, respectively, represent depth of the tunnel and its diameter. In addition to the model size, proper selection of the suitable constitutive law plays an important role in the determination of the tunneling-induced settlements. Chow (1994) selected two linear-elastic and elastoplastic constitutive models to numerically analyze the tunneling problem. The performance of the linear-elastic model with a linearly increasing soil stiffness was realized to be more accurate [24]. Calabresi et al. presented that numerical models developed based on the simple and elastoplastic constitutive laws lead to a wider settlement profile and are not suitable for studying the soil inelastic behavior in small strain conditions [25]. Guedes and Santos Pereira adopted a linear elastoplastic constitutive law to model the second line of Shanghai metro and observed that their settlement profiles were not in close agreement with the field observations [26]. Hence, in this study, special consideration is paid to the proper selection of 
the model size, also the appropriate constitutive law. In addition, as described, there are some studies on the twoand three-dimensional numerical analysis of the settlements induced by the tunnel advancement considering the tunnelstructure interaction available in the literature $[7,8,10,11,15,20-23]$. But there are limited ones when introducing a detailed, three-dimensional geometry for the superstructure into the problem. As far as the authors know, there is not such an investigation which adopts the described advantages and employs a finite difference method to investigate the longitudinal settlement profile. Fargnoli et al. focusing on a case study shed some light on the problem [27]. But, to come into a comprehensive and accurate conclusion, such a study should be accompanied by an indepth parametric study to investigate effects of different parameters of the tunnel and the superstructure. Thus, this paper presents a parametric study to show the role of the depth of tunneling, tunnel diameter, and the geometry of the superstructure using a well-validated three-dimensional finite difference investigation. As there has not been a threedimensional finite difference framework in the literature to parametrically assess effects of the tunnel advancement on the performance of structural members of the superstructure, this study presents such evaluations as an important novelty.

\section{Definition of the Problem and Research Significance}

This paper utilizes finite difference modeling approach and FLAC 3D [28] software to comprehensively investigate the soil-sequential tunneling-superstructure interaction problem. Like the previous studies on the sequential TBM tunneling in urban areas, it is assumed that the whole tunnel cross section is excavated in a single step and the tunnel advancement is carried out in a staged construction manner with a constant round length. The thickness of the installed concrete lining is assumed to be $40 \mathrm{~cm}$ and the installation of the permanent support system has a delay step relative to the excavation steps. As there was not a common agreement between researchers on the suitable model size and the constitutive law, as the preliminary phase, a considerable number of numerical models with different sizes and governing constitutive laws were built, to evaluate the sensitivity of the settlement profile to these two factors. In this regard, free-field analyses are carried out for a variety of model sizes; also constitutive laws and then longitudinal settlement profiles with the advancement of tunneling are calculated and analyzed for each of the studied cases as a basis for the selection of the proper size of the model and for the preliminary assessment of the selected constitutive law prior to its characterization (due to the large number of the studied cases, the results are not presented here). Model dimensions and constitutive parameters presented in the paper are those attained from the intensive preliminary investigations. Longitudinal settlement profile of the ground with the sequential tunneling advancement is also developed with the consideration of the effect of the real geometry of the superstructure as a contribution of the present study. Besides, the impact of tunnel advancement on the structural elements of the superstructure is comprehensively investigated. In this regard, developed numerical models are first well validated against available theoretical and other numerical methods. Next, parametric studies are done to fill the gap between available studies, each assessing one or more of the affecting factors. To do this, effects of depth of tunneling, diameter of the tunnel, and the geometry (number of stories) of the superstructure on the longitudinal settlement profile are all addressed in a unique study. In addition, generation of the excess internal structural forces and moments in the superstructure due to sequential tunneling is evaluated.

\section{Validation of Numerical Models}

Validation of the conducted numerical studies is carried out in three different phases. The first following section deals with two-dimensional verifications (both analytical and numerical ones), while the second one compares the results obtained from the three-dimensional numerical studies with the available theoretical relationships.

\subsection{Two-Dimensional Validation of Models with Simplified} Cases. In this section, two-dimensional models are developed to validate the accuracy of the numerical modeling with available theoretical and numerical solutions.

3.1.1. Comparison of Ground Reaction Curve with Hoek's Analytical Solution. Due to tunnel excavation, existing stress field will be disturbed and redistributed around the excavated tunnel and, consequently, excavated area can converge. The first validation phase investigates displacements occurring at the tunnel crown, sidewalls, and floor based on the dimensionless internal tunnel pressure (ratio of tunnel support pressure, $P_{i}$, to the initial field stress, $P_{0}$ ), known as the convergence-confinement graph of tunnels. Calculated graphs are then compared to the analytical solution presented by Hoek [29]. According to Hoek, soil failure can be addressed using the following relationship based on the classical Mohr-Coulomb criterion [29]:

$$
\sigma=\sigma_{\mathrm{cm}}+K,
$$

where

$$
\begin{array}{r}
\sigma_{\mathrm{cm}}=\frac{2 c \cos \phi}{1-\sin \phi} \\
K=\frac{1+\sin \phi}{1-\sin \phi}
\end{array}
$$

where $\sigma_{\mathrm{cm}}$ is the uniaxial compressive strength of materials (in $\mathrm{MPa}$ ), $c$ is the cohesion (in $\mathrm{MPa}$ ), and $\phi$ represents the friction angle. The minimum internal lining pressure (critical pressure, $P_{\mathrm{cr}}$ ), where the material behavior changes from elastic to plastic, can be calculated using Equation (3). For a tunnel with the radius of $R$ and under isotropic, farfield in situ stress of $p_{0}$ and an inner pressure of $P_{i}$ (from the internal support to the tunnel wall), if $P_{i}>P_{\mathrm{cr}}$ (Figure 1), the 


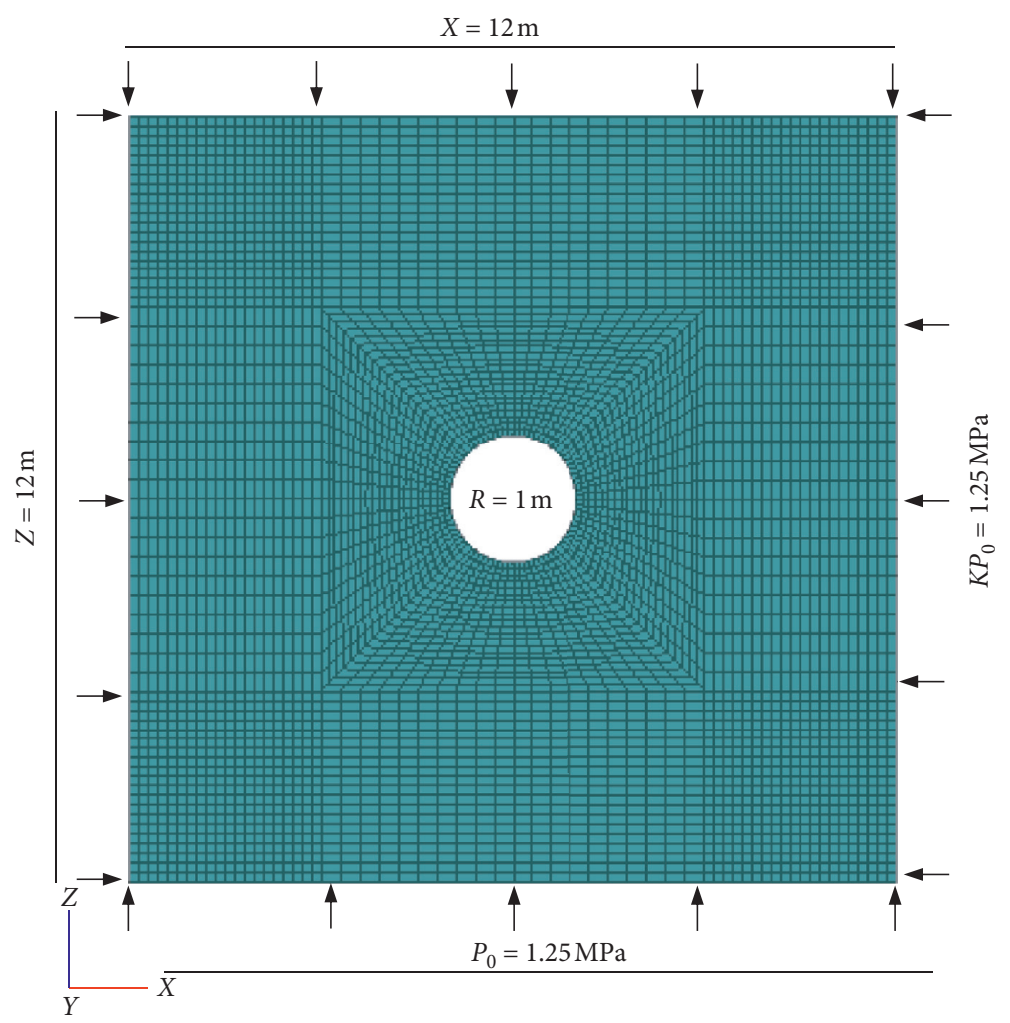

FIGURE 1: The geometry of the two-dimensional model used to perform the validation.

behavior of materials around the tunnel will be elastic and the radial displacement around the tunnel can be calculated as presented in the following equation:

$$
\begin{aligned}
& P_{\mathrm{cr}}=a\left(\frac{2 P_{0}-\sigma_{\mathrm{cm}}}{1+K}\right), \\
& u_{i e}=\frac{R(1+v)}{E}\left(P_{0}-P_{i}\right),
\end{aligned}
$$

where $v$ and $E$, respectively, represent Poisson's ratio and Young's modulus of material.

According to Figure 1, a two-dimensional model with the dimensions of $12^{\mathrm{m}} \times 12^{\mathrm{m}}$ with a $2 \mathrm{~m}$ in diameter circular tunnel is considered for the modeling purposes. Poisson's ratio and Young's modulus of materials, respectively, were assumed to be $v=0.22$ and $E=60 \mathrm{MPa}$. Far-field, in situ stress is $P_{0}=1.25 \mathrm{MPa}$. Regarding the comparison presented in Figure 2, there are suitable consistency between results of the numerical analysis and the analytical relationship.

\subsubsection{Comparison of Settlements with the Research} Conducted by Dragojević. In this section, a two-dimensional model is developed to model the problem previously solved by Dragojević as the second validation phase. Geotechnical and geomechanical properties of the layered studied soil are presented in Table 1. Dragojević, using finite element Diana software, studied the longitudinal and transverse surface settlements and compared two-dimensional and three-dimensional modeling results and found that the suitable stress release percentage should be $\beta=63 \%$ for his twodimensional models [30]. Like dimensions and features of the original problem, a $50^{\mathrm{m}} \times 80^{\mathrm{m}}$ model is developed (Figure 3), in which the depth of tunneling and the tunnel diameter are, respectively, $15 \mathrm{~m}$ and $6 \mathrm{~m}$ and the stress release factor is $63 \%$. Also materials are assumed to follow an elastoplastic behavior with the Mohr-Coulomb criterion.

After tunnel excavation, the concrete lining is installed. A linear-elastic model is used as the governing constitutive law for the support system. The thickness of concrete is $0.35 \mathrm{~m}$ and other mechanical properties of the support system are $v=0.15, E=15 \mathrm{GPa}$, and $P=2500 \mathrm{~kg} / \mathrm{m}^{3}$. As presented in Figure 4, there is a suitable agreement between the results of the finite difference modeling of the present study and the finite element modeling of Dragojević [30].

3.2. Three-Dimensional Validation of the Model with Analytical Relationships. As the free-field analysis is the preliminary step of all the analyses conducted in the present study, the three-dimensional model of a tunnel is built and compared to the analytical relationship of the longitudinal ground settlement presented by Panet and Guento as shown in the following equation:

$$
S_{v}(x)=S_{v \max }(x)\left(0.28+0.72\left(1-\left(\frac{0.84}{0.84+x^{*}}\right)^{2}\right)\right)
$$

where $X$ is the distance between the desired section and the tunnel face, $S_{v}(X)$ presents the longitudinal ground settlement across the excavation direction, $S_{v \max }(X)$ is the 


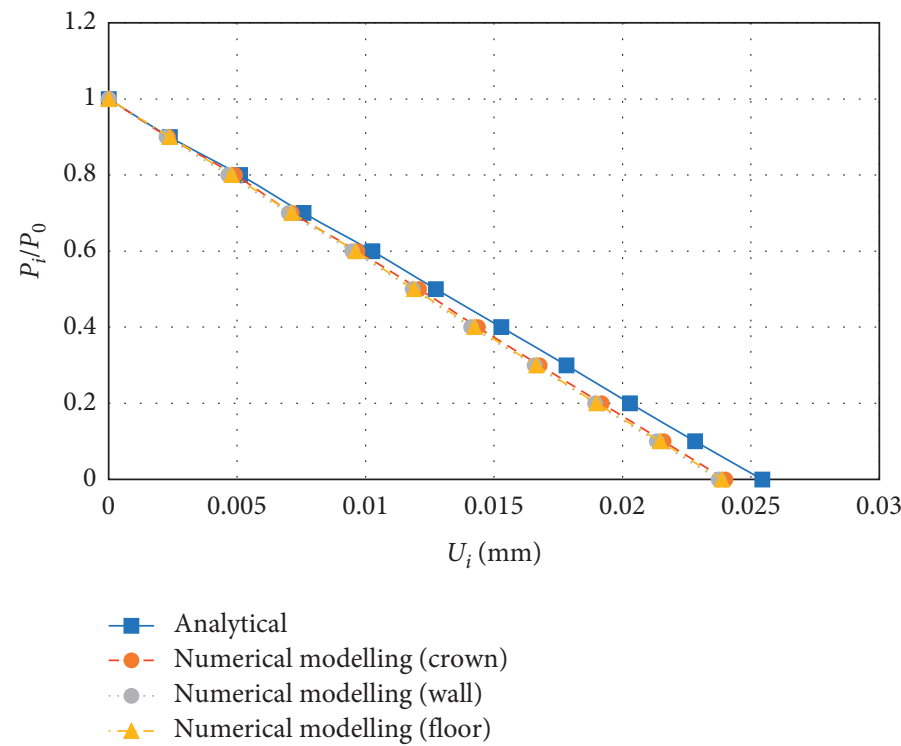

FIGURE 2: Comparison between the ground reaction curves calculated from the two-dimensional finite difference modeling and the analytical relationships of Hoek.

TABLE 1: Geotechnical and geomechanical properties of the material [30].

\begin{tabular}{lccccc}
\hline Parameter & Index & Unit & First layer $\left(h_{1}\right)$ & Second layer $\left(h_{2}\right)$ & Third layer $\left(h_{3}\right)$ \\
\hline Coefficient of lateral soil pressure & $k$ & - & 0.65 & 0.85 & 0.58 \\
Density & $\rho$ & $\mathrm{kg} / \mathrm{m}^{3}$ & 1850 & 2000 & 2000 \\
Friction angle & $\phi$ & $(\circ)$ & 23 & 20 & 25 \\
Cohesion & $c$ & $\mathrm{kPa}$ & 18 & 15 & 60 \\
Young's modulus & $E$ & $\mathrm{MPa}$ & 10 & 0.3 & 60 \\
Poisson's ratio & $v$ & - & 0.4 & 0.3 \\
\hline
\end{tabular}

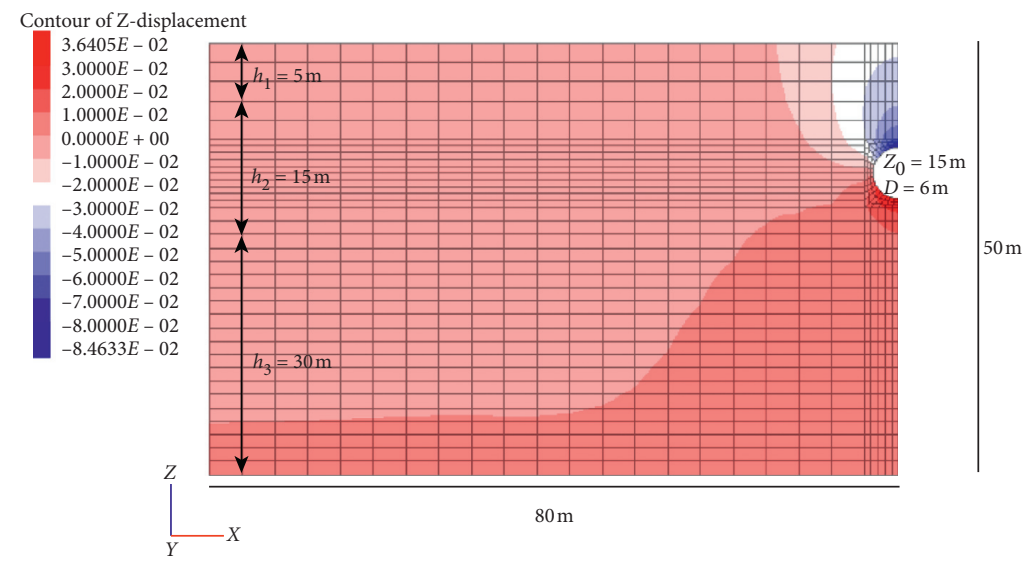

FiguRE 3: Geometry and meshing of the two-dimensional model used for validation, as well as vertical displacement contour.

maximum longitudinal ground settlement at the steady state condition, and $X^{*}=(X / R)$ ( $R$ is the tunnel radius).

Unlu and Gercek presented a continuous function for the prediction of the longitudinal settlement in the elastic condition as shown in Equation (6). In Equation (6), $X^{*}=0$ represents the position of the tunnel face; also, negative and positive $X$ values, respectively, stand for the points in front and behind the tunnel face [32].

$$
S_{v}(x)=S_{v \max }(x)\left[(0.22 v+0.19)+A_{b}\left(1-\left(\frac{B_{b}}{\left(B_{b}+x^{*}\right)}\right)^{2}\right)\right], \quad\left(x^{*}>0\right),
$$

where $v$ is Poisson's ratio of the ground and

$$
\begin{aligned}
& A_{a}=-(0.22 v+0.19), \\
& B_{b}=0.39 v+0.65
\end{aligned}
$$




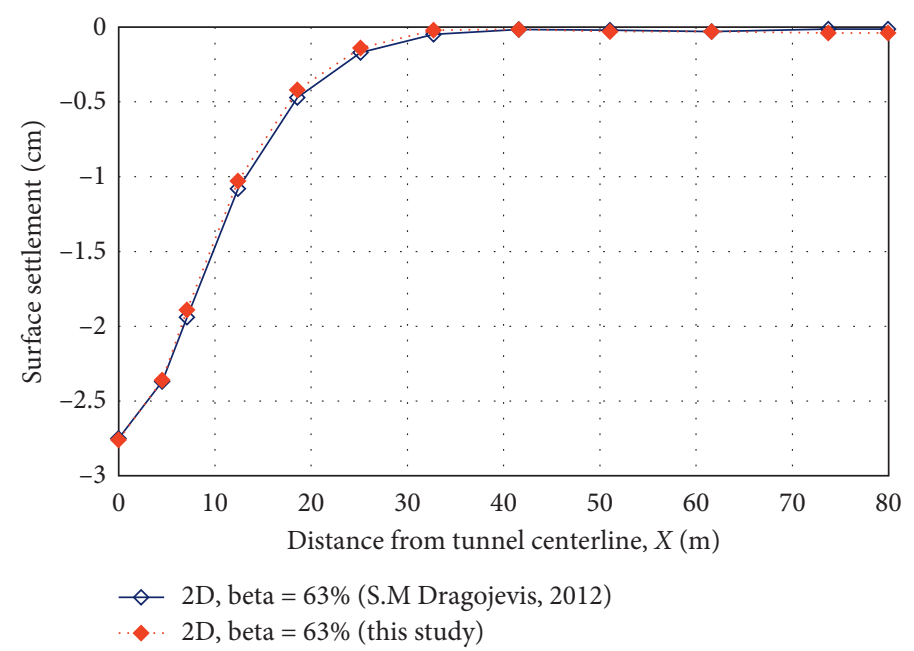

Figure 4: Comparison between the ground's transverse settlement profile of the present study and Dragojević [30].

Geometry of the model is discretized using 8-node, quadratic grids. Model dimensions are, respectively, $80 \mathrm{~m}$, $140 \mathrm{~m}$, and $85 \mathrm{~m}$ in width, length, and height. The depth and the diameter of the tunnel are, respectively, $30 \mathrm{~m}$ and $6 \mathrm{~m}$. Vertical side boundaries are fixed in the horizontal direction, while the bottom boundary is fixed in both horizontal and vertical directions. After the generation of in situ stresses, the tunnel excavation is conducted in $2 \mathrm{~m}$ intervals and continues to the last section, which has $80 \mathrm{~m}$ distance from the initial side boundary. Mechanical behavior of the concrete support system is linear elastic. Its thickness is $0.4 \mathrm{~m}$, and other elastic parameters of the support system, which is installed with a delay step: $v=0.15, E=20 \mathrm{GPa}$, and $P=2500 \mathrm{~kg} / \mathrm{m}^{3}$. Figure 5 compares the results obtained from the numerical modeling of the present study with the analytical relationships proposed in (6) and (7). $X$ direction is considered as the excavation direction. It should be noted that the relationship suggested by Panet and Guento (1982) is only applicable for the estimation of the settlements behind the tunnel face and cannot predict values of the settlement for those points located in front of the tunnel face. As shown in Figure 5, results are in a good agreement and the superiority of the numerical model in tracking the gradual settlement calculation near to the tunnel face is obvious.

\section{Consideration of Superstructure: Three- Dimensional Modeling versus Free-Field Case}

In this section, the free-field case, in which the effect of superstructure on the tunneling-induced ground settlement is disregarded, is compared to the case of the detailed threedimensional modeling of the superstructure. As the common features used in all the cases, model dimensions are, respectively, $140 \mathrm{~m}, 140 \mathrm{~m}$, and $85 \mathrm{~m}$ in $X, Y$, and $Z$ directions (Figure 6). Bottom boundary is fixed in both horizontal and vertical directions, while side boundaries are restricted from displacements in the horizontal direction. In the cases of the presence of the structure, the structure is symmetrically placed over the tunnel (with regard to the tunnel axis across $X$-direction). Three-dimensional geometry of the superstructure is built using structural beam elements and beam-to-column connections are considered rigid. All the modeled beams and also all the columns (in different stories) have the same cross-sectional shape and features. All the spans are $6 \mathrm{~m}$ in length and the height of all stories is $3 \mathrm{~m}$. Table 2 presents geotechnical and geometrical properties of the studied ground and tunnel, while Table 3 shows mechanical and geometrical specifications of the beam-column elements used in the modeling of 8-story concrete building (applied as a benchmark for studying the real geometry of the superstructure).

The longitudinal ground profiles of the settlement for the two cases of existence of the structure and the free field obtained from numerical analysis are shown in Figure 7. In this figure, the longitudinal profiles of the settlement are shown for every ten meters of the tunnel advance and by arrow, and the position of the tunnel front surface is marked on each graph. Based on the results obtained for the tunneling in the free-field condition, with the tunnel advancements, longitudinal settlement profiles reach a steady state and all the profiles tend to a peak settlement value. In contrast, the results gained from the case of the threedimensional superstructure modeling show that, with the tunnel advancement, there is a progressive trend in settlements until the tunnel face passes through the location of the superstructure. With advancing the tunnel face toward the location of the structure, differences between free-field settlements and the superstructure's case increase and the maximum difference corresponds to the middle of the superstructure. In this state, the superstructure experiences an unbalanced settlement with respect to the tunnel face. After that, with passing the tunnel face through the location of the superstructure, this unbalanced settlement decreases. Also, the maximum occurring settlement refers to the state that the tunnel face completely passes through the superstructure. In addition, despite the case of free-field settlements, there is not a steady state condition prior to passing through the structure. GF and STSI, respectively, refer to the "Ground-Free-Field" and "Soil-Tunnel-Superstructure- 


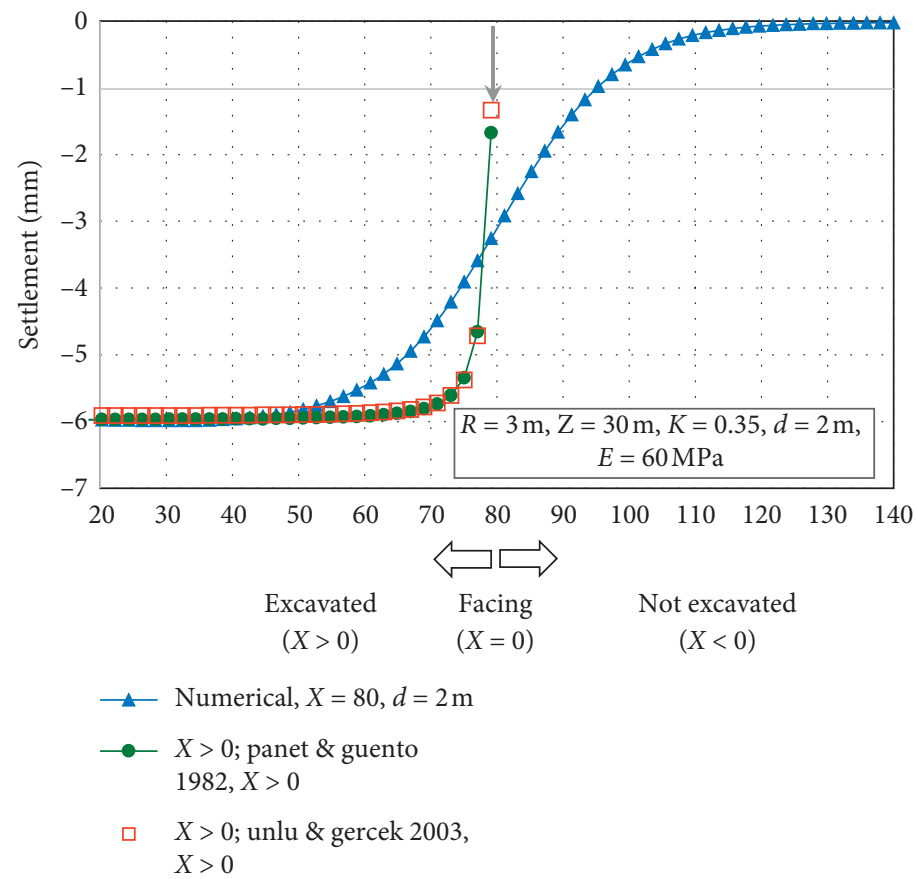

Figure 5: Comparison between the longitudinal ground settlement obtained from the numerical model and the analytical relationships.

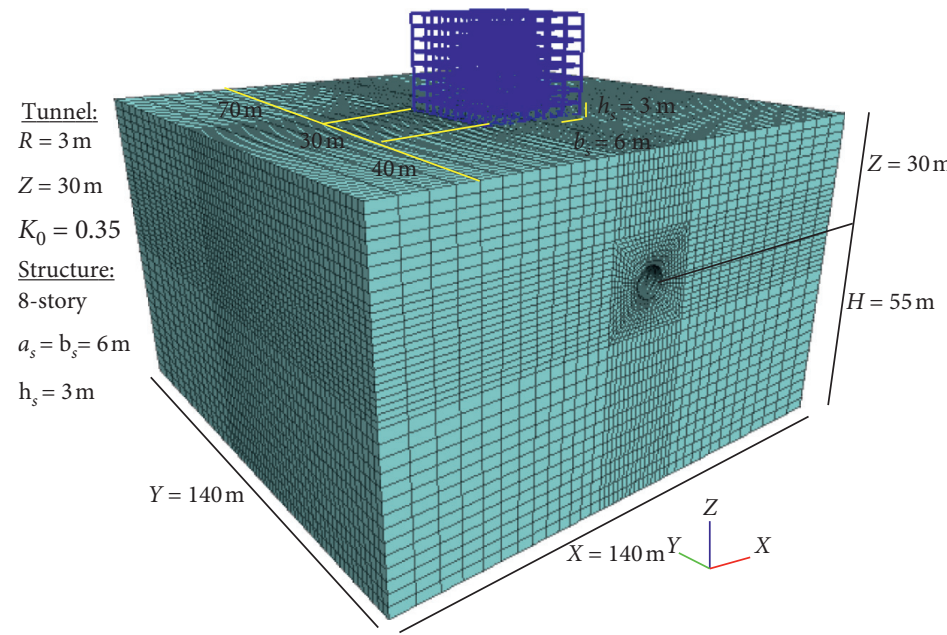

FIgURE 6: Geometry and meshing of three-dimensional models and surface structures.

TABLE 2: Geotechnical and geometrical properties of the studied ground and tunnel.

\begin{tabular}{lccc}
\hline Parameter & Index $X$ & Unit & Value \\
\hline Coefficient of lateral earth pressure & $k$ & - & 0.35 \\
Density of the ground & $\rho$ & $\mathrm{kg} / \mathrm{m}^{3}$ & $(\circ)$ \\
Ground friction angle & $\phi$ & $\mathrm{kPa}$ & $\mathrm{MPa}$ \\
Ground cohesion & $c$ & - & 30 \\
Ground Young's modulus & $E$ & $\mathrm{~m}$ & 30 \\
Ground Poisson's ratio & $v$ & $\mathrm{~m}$ & 60 \\
Radius of tunnel & $R$ & $\mathrm{~m}$ & 3 \\
Depth of tunnel & $Z$ & $\mathrm{~kg} / \mathrm{m}^{3}$ & 30 \\
Round length & $L_{\text {exc }}$ & $\mathrm{GPa}$ & 22 \\
Density of support system & $P$ & - & 2500 \\
Young's modulus of support system & $E$ & $\mathrm{~m}$ & 25 \\
Poisson's ratio of support system & $v$ & 0.15 \\
Thickness of support system & $t$ & 0.4 \\
\hline
\end{tabular}


TABLE 3: Geometrical and mechanical properties of the concrete beam and column elements.

\begin{tabular}{lccc}
\hline Parameter & Index & Unit & Value \\
\hline Young's modulus & $E$ & $\mathrm{GPa}$ & 25 \\
Poisson's ratio & $v$ & - & 0.25 \\
Cross section of beams & $B \times H$ & $\mathrm{~cm}^{2}$ & $20 \times 20$ \\
Cross section of columns & $B \times L$ & $\mathrm{~cm}^{2}$ & $20 \times 40$ \\
Moment of inertia of the beams $(y)$ & $I_{y}$ & $\mathrm{~cm}^{4}$ & 106666.7 \\
Moment of inertia of the beams $(z)$ & $I_{z}$ & $\mathrm{~cm}^{4}$ & 26666.7 \\
Moment of inertia of the columns & $I_{y}=I_{Z}$ & $\mathrm{~cm}^{4}$ & 213333.3 \\
\hline
\end{tabular}

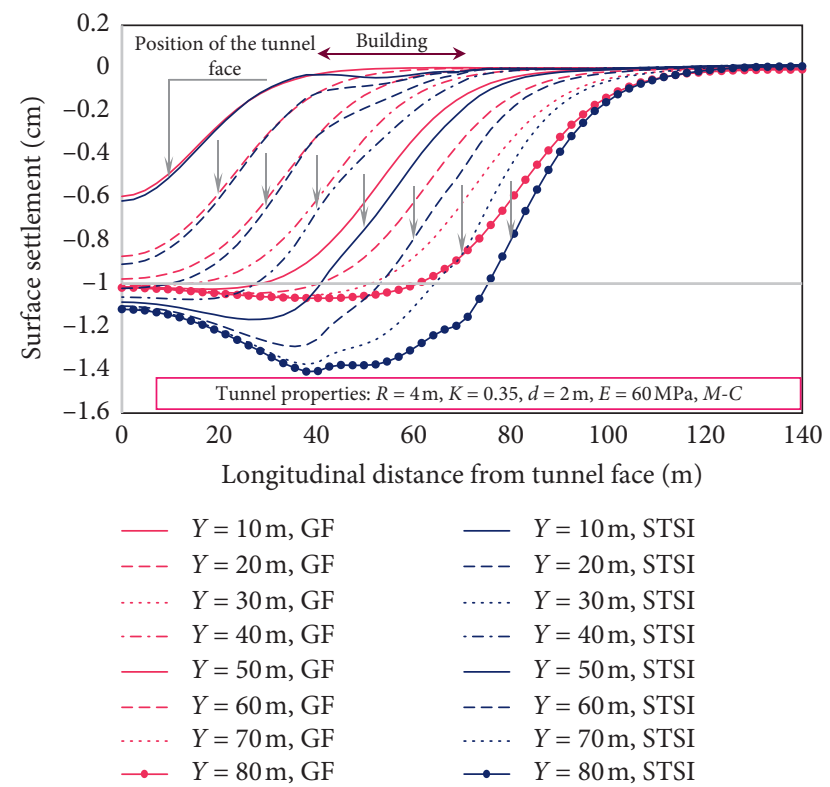

Figure 7: Comparison between longitudinal tunneling-induced settlement profiles of the free-field and three-dimensional superstructure cases with regard to the tunnel advancement.

Interaction" cases. Figures 8 and 9 present displacement and stress contours in the vertical direction for the case of an 8story concrete structure, respectively.

\section{Results and Discussion}

As described, proper consideration of the superstructure plays an important role in the solution of the soil-tunnel-superstructure problem. In this regard, the three-dimensional approach for the modeling of the superstructure is considered for the parametric analyses. Hence, the well-validated threedimensional finite difference model described in the previous sections is adopted to study effects of the diameter of tunnel, the depth of tunneling, and the geometry of the superstructure on the tunneling-induced ground settlements. Moreover, the vulnerability of the superstructure against tunneling effects is discussed characterizing internal forces and moments of its structural elements.

5.1. Effect of the Tunnel Diameter on the Longitudinal Settlement Profile. In this section, assuming that all other parameters are kept constant, the problem is solved for three different tunnel diameters, $8 \mathrm{~m}, 12 \mathrm{~m}$, and $16 \mathrm{~m}$. As shown in Figures $10-12$, with increasing the tunnel diameter, settlements increase considerably. As Figures 10-12 simultaneously show settlements of both free-field and superstructure-included cases, it is understood that, with increasing the diameter of the tunnel, the effect of the superstructure on the tunneling-induced settlements increases.

Comparing different cases, effects of the diameter of the tunnel on the tunneling-induced settlements are clearly shown in Figure 13. As depicted, its effect is even more considerable below the superstructure.

5.2. Effect of the Depth of Tunneling on the Longitudinal Settlement Profiles. To investigate the effect of the depth of the tunneling, three different tunneling depths are modeled $(15 \mathrm{~m}, 30 \mathrm{~m}$, and $45 \mathrm{~m})$ and the obtained results are separately presented in Figures 14-16 considering both free-field and soil-superstructure interaction conditions.

Figure 17 compares settlement profiles for different tunneling depths. It is shown that, with increasing the depth of tunneling, settlement increases, but the effect of the superstructure on the tunneling-induced settlements decreases. In other words, for the tunneling depths higher than $45 \mathrm{~m}$, the interaction effects of the tunnel excavation and the superstructure decrease and the general trends of STSI cases will be like those observed for free-field cases.

5.3. Effect of the Geometry (Number of Stories) of the Superstructure on the Longitudinal Settlement Profile. 6-, 8-, $12-$, and 17-story structures are considered for evaluating the impact of the geometry (number of stories) of the superstructure on the longitudinal settlement profiles. Dimensions of foundations for these 6-, 8-, 12-, and 17-story structures are, respectively, $18^{\mathrm{m}} \times 18^{\mathrm{m}}, 30^{\mathrm{m}} \times 30^{\mathrm{m}}, 30^{\mathrm{m}} \times 30^{\mathrm{m}}$, and $42^{\mathrm{m}} \times 42^{\mathrm{m}}$. Settlement profiles are presented in Figures 18-21. Also, Figure 22 compares effects of all four studied cases (different numbers of stories) in a single figure. It is observed that when the tunnel face completely passes through the superstructure, longitudinal settlement profile of the 6-story building shows a slight heaving behavior, which can be attributed to the low number of stories and, hence, the enhanced stiffness of the superstructure. In such condition, the settlement profile is quite identical to the freefield graph. With increasing the number of stories and the weight of the structure, maximum settlement of the ground significantly increases and the heaving behavior (under the structure) decreases. Also, for structures with more than 17 stories, there is a considerable difference between the settlement profiles of free-field and soil-superstructure interaction cases.

5.4. Effect of Sequential Tunneling on the Internal Forces and Displacements of the Superstructure. Tunneling-induced ground settlements cause excess internal forces and moments in the structural elements of the superstructure. In this section, the benchmark model geometry and properties described in the previous sections are used to evaluate 


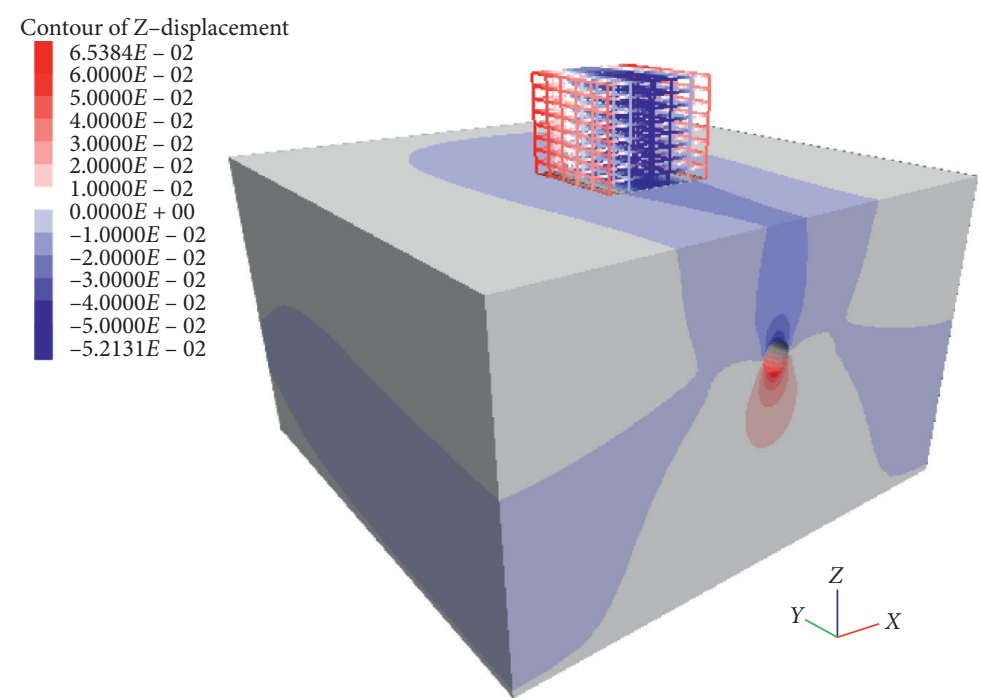

FIGURE 8: Displacement contours in the vertical direction induced by the tunnel advancement for the model of the tunnel with an 8-story concrete structure.

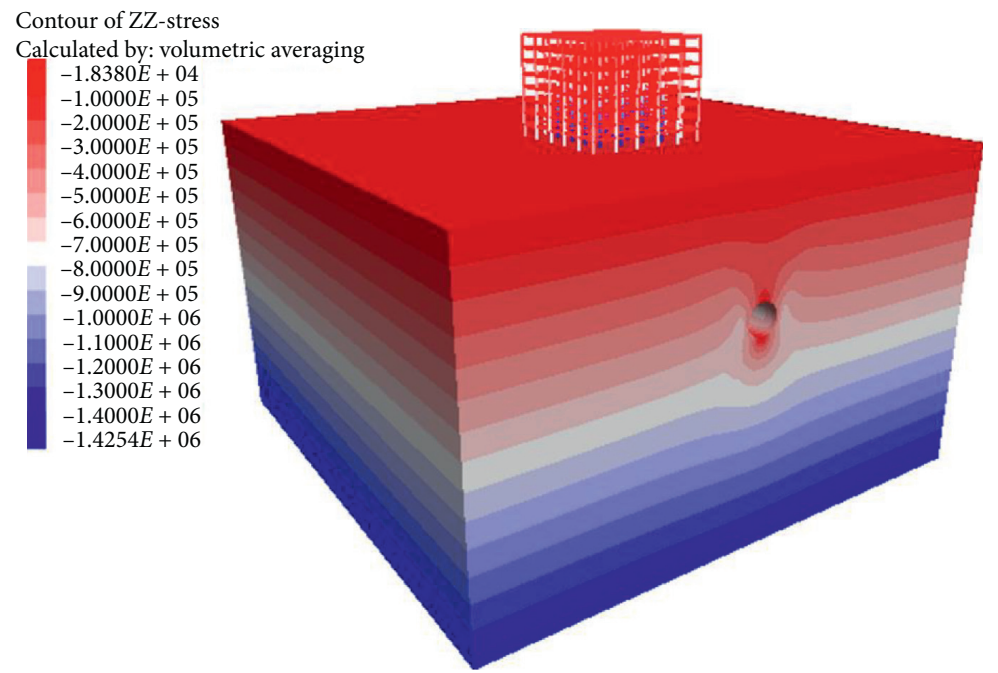

FiguRE 9: Stress contours in the vertical direction induced by the tunnel advancement for the model of tunnel with an 8-story concrete structure.

internal forces, bending moments and displacements of beams and columns of the superstructure with the tunnel advancement. Figure 23 shows the geometry of the tunnel and the 8 -story superstructure, which is symmetric in the $X$ direction with respect to the tunnel axis. Benchmark structural elements investigated in this paper, which are selected from the ground floor, are located above the tunnel axis and in the point with the coordination of $Y=40 \mathrm{~m}$ (distance of the element from the tunnel opening). The studied beam and columns are, respectively, shown using $B_{1}$ and $C_{2}, C_{3}, C_{4}$ symbols (Figure 23) and the variation of the axial force and the vertical displacement of the columns $C_{2}, C_{3}, C_{4}$; also, the bending moment and the vertical displacement of the beam $B_{1}$ (at the beginning, middle, and the end of the beam) with the tunnel advancement are then depicted.
Vertical displacement of the column $C_{2}, C_{3}, C_{4}$ while the tunnel passes through the structure is shown in Figures 24-26, respectively. As expected from the settlement profiles, with advancing the tunnel face, the vertical displacement of the column increases. The rate of this increase will be even more, while the tunnel face is under the superstructure. Comparing the diagrams of these three figures, it can be seen that the shorter the distance from the column to the axis of the tunnel, the more the column settles. For example, the maximum vertical displacement of column $C_{2}$ has the shortest distance to the axis of the tunnel, $1.4 \mathrm{~cm}$, while for columns $C_{3}$ and $C_{4}$ it is $1.1 \mathrm{~cm}$ and $0.83 \mathrm{~cm}$, respectively.

The diagrams in Figures 27-29 show the changes in the axial force of these three columns against the advance of the tunnel. It is observed that the $C_{2}$ column settlement causes 


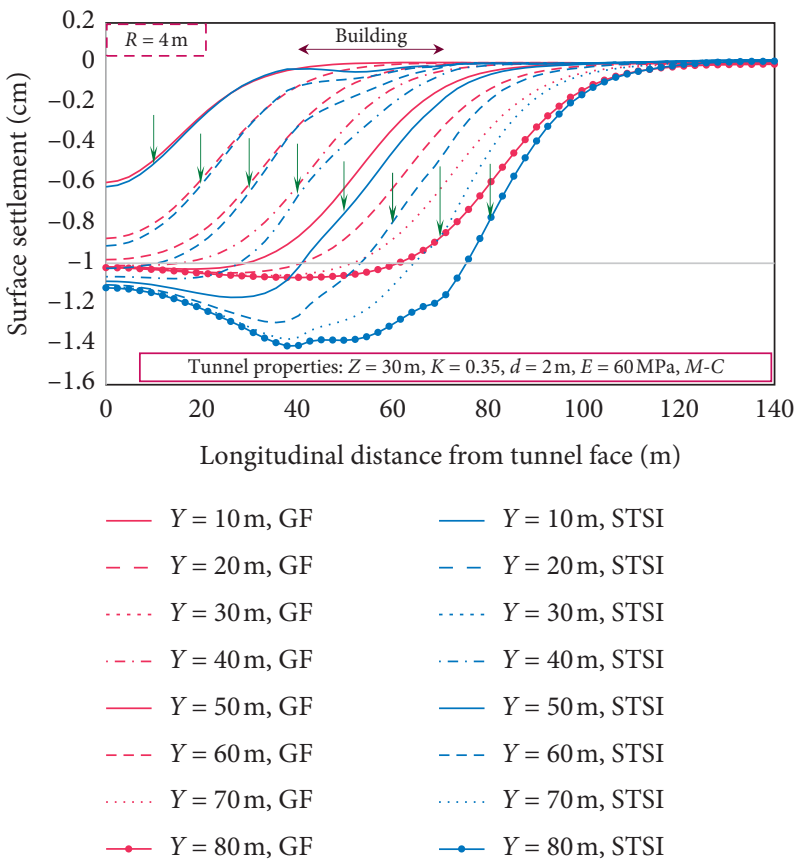

Figure 10: Comparison of longitudinal settlement profiles between free-field and superstructure-included cases for the tunnel with the diameter of $8 \mathrm{~m}$.

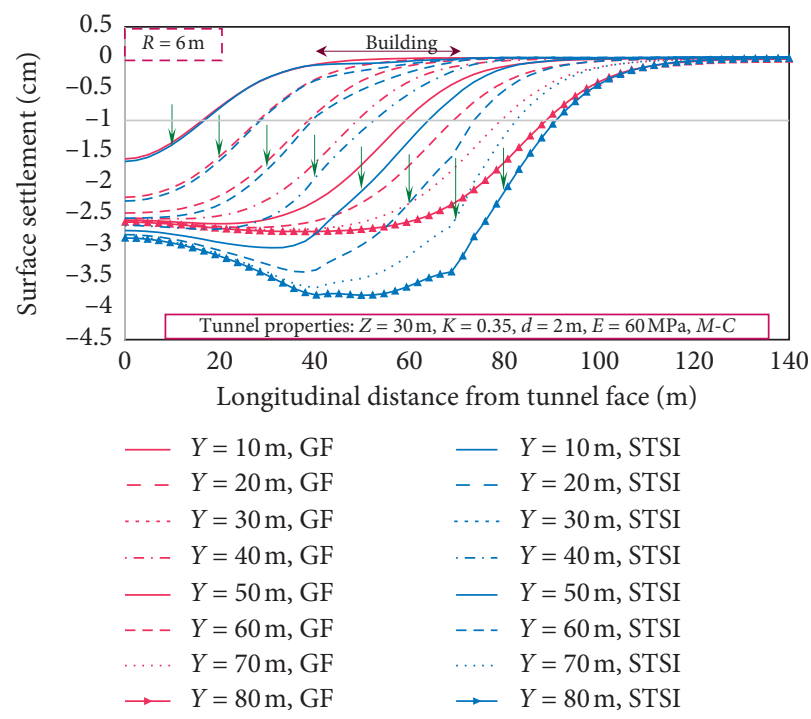

FIgURE 11: Comparison of longitudinal settlement profiles between free-field and superstructure-included cases for the tunnel with the diameter of $12 \mathrm{~m}$.

some of the axial force of this column to be released and the absolute value of the axial force decreases as the tunnel progresses (Figure 27). The axial force released from this column is transmitted by beams to adjacent columns. In the case of column $C_{3}$ in Figure 28, it can be seen that as the tunnel progresses, there is a decreasing trend in absolute axial force in this column, but when the tunnel is placed under the structure, this trend slows down and is almost constant. This is because the transfer of axial load from column $C_{2}$ to this column modulates the decreasing trend of the axial force of this column. Next, for column $C_{4}$, it can be seen in Figure 29 that, unlike the two adjacent columns, the absolute magnitude of its axial force increases as the tunnel progresses. In other words, although the subsidence of this column reduces its 


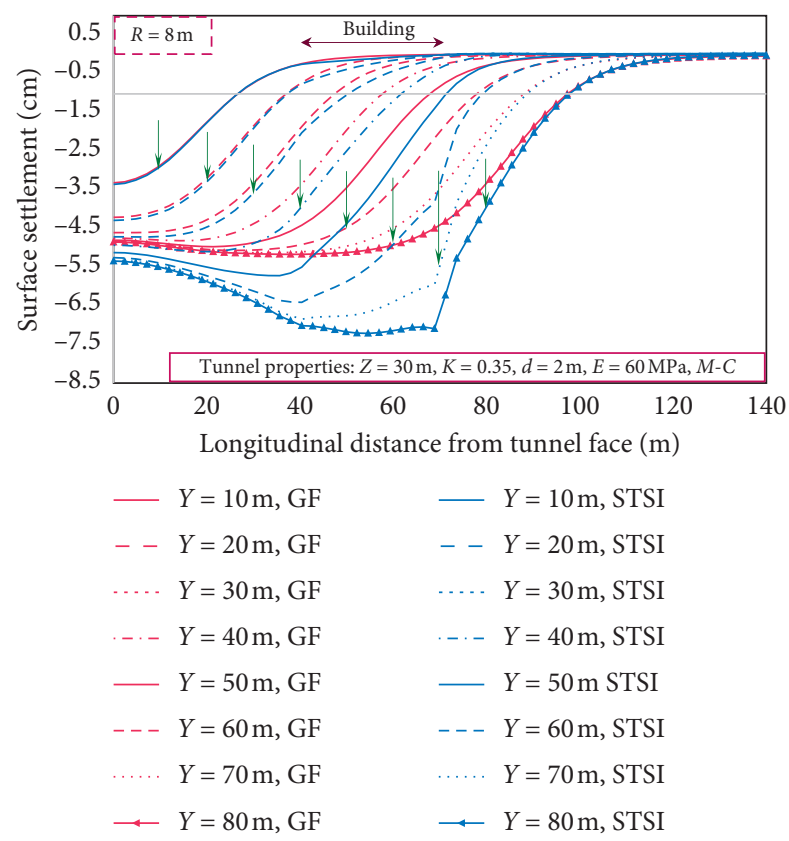

Figure 12: Comparison of longitudinal settlement profiles between free-field and superstructure-included cases for the tunnel with the diameter of $16 \mathrm{~m}$.

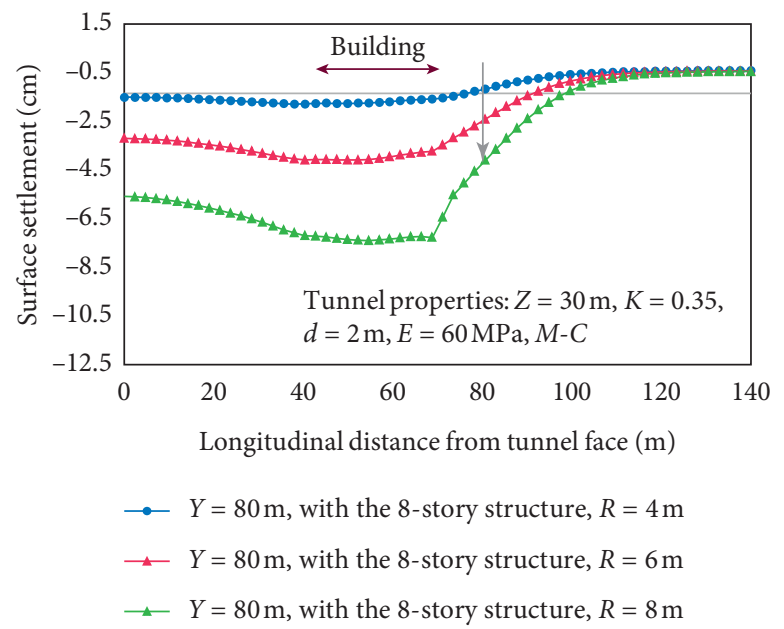

FIGURE 13: Comparison of the longitudinal tunneling-induced settlement profiles under the structure for different diameters of the tunnel.

axial force, the share of axial force from the two columns $C_{2}$ and $C_{3}$ ultimately increases its axial force.

The axial force transmission is done by the middle beam; because of this transmission, the middle beam will experience a higher bending moment to carry on the force from the side column to the other ones. Figure 30 shows the variation of the bending moment at three different points of the beam versus the tunnel advancement. 


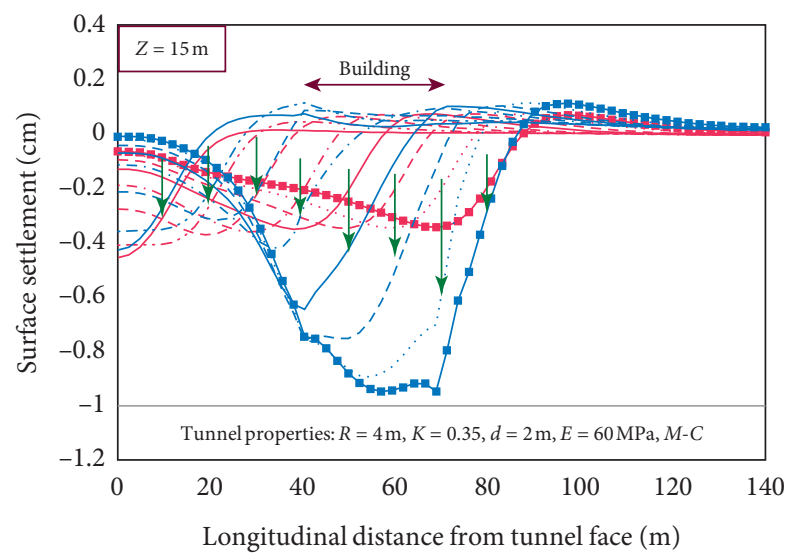

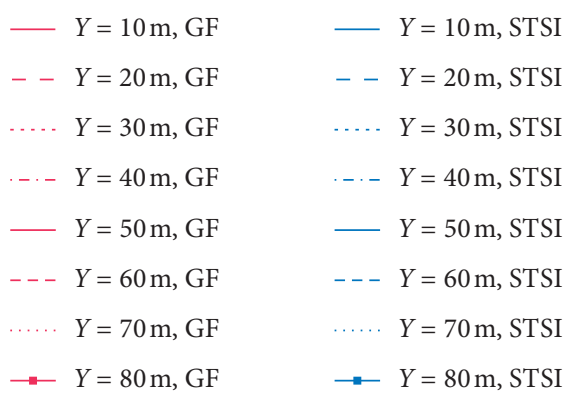

Figure 14: Comparison of longitudinal settlements between free-field and superstructure-included cases for the tunneling depth of $15 \mathrm{~m}$.

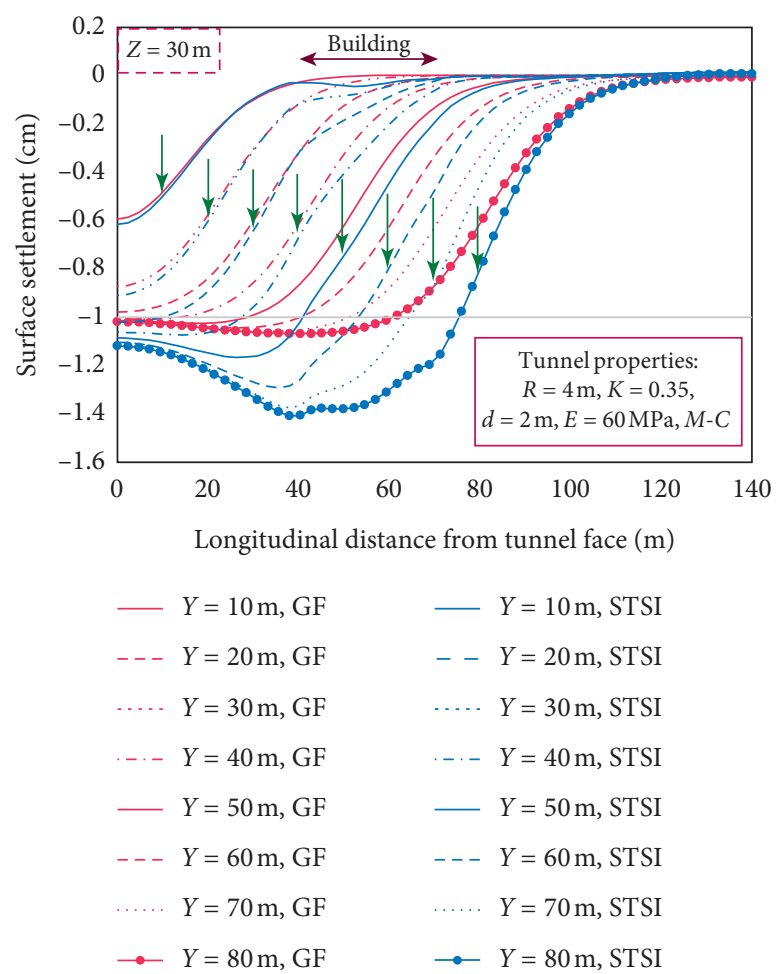

FIGURE 15: Comparison of longitudinal settlements between free-field and superstructure-included cases for the tunneling depth of $30 \mathrm{~m}$. 


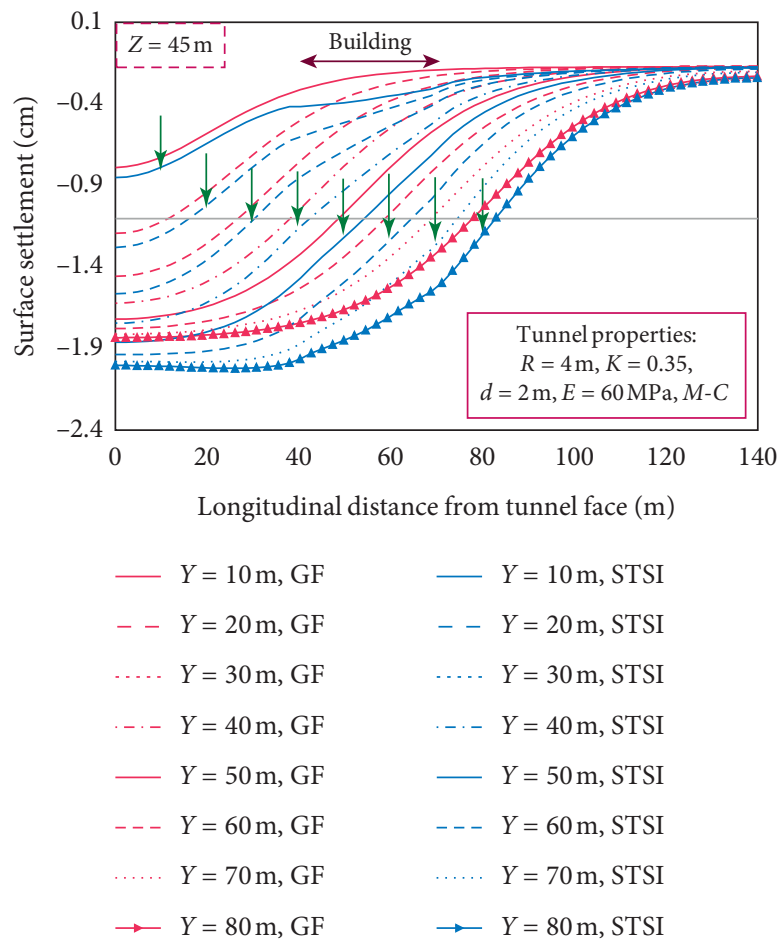

FIGURE 16: Comparison of longitudinal settlements between free-field and superstructure-included cases for the tunneling depth of $45 \mathrm{~m}$.

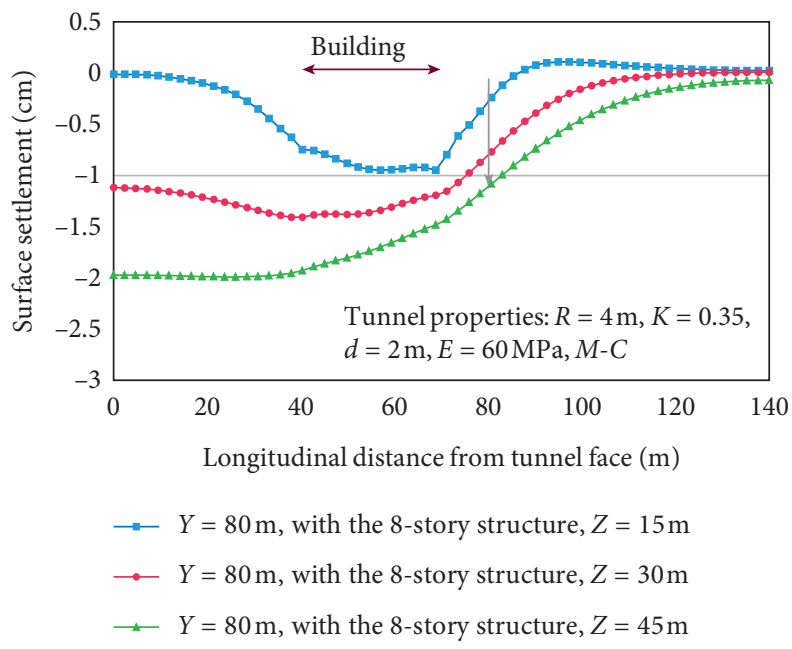

Figure 17: Comparison of the longitudinal tunneling-induced settlement profiles for different depths of tunneling. 


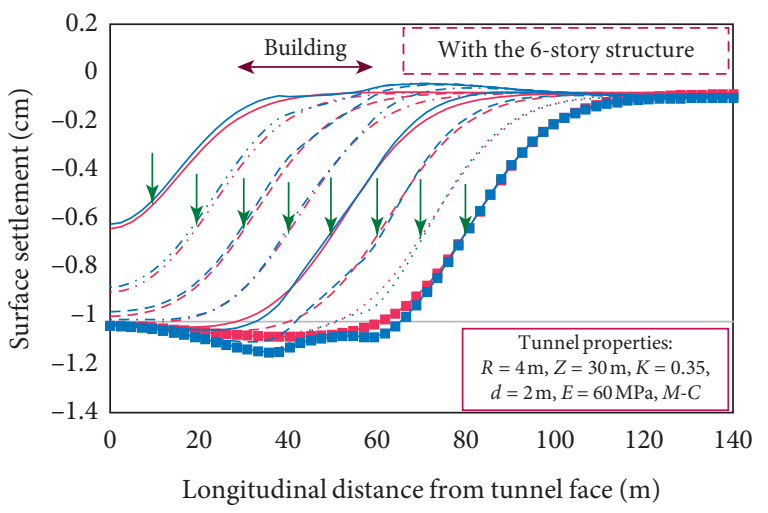

$$
\begin{aligned}
& -Y=10 \mathrm{~m}, \mathrm{GF} \quad Y=10 \mathrm{~m}, \mathrm{STSI} \\
& - \text { - } Y=20 \mathrm{~m}, \mathrm{GF} \quad-\quad Y=20 \mathrm{~m}, \mathrm{STSI} \\
& \text { … } Y=30 \mathrm{~m}, \mathrm{GF} \quad \ldots . . Y=30 \mathrm{~m}, \mathrm{STSI} \\
& \text {... } Y=40 \mathrm{~m}, \mathrm{GF} \quad \ldots Y=40 \mathrm{~m} \text {, STSI } \\
& \text { - } Y=50 \mathrm{~m}, \mathrm{GF} \quad \mathrm{Y}=50 \mathrm{~m}, \mathrm{STSI} \\
& \text {-- } Y=60 \mathrm{~m}, \mathrm{GF} \quad \ldots Y=60 \mathrm{~m}, \mathrm{STSI} \\
& Y=70 \mathrm{~m}, \mathrm{GF} \quad \ldots . . Y=70 \mathrm{~m}, \mathrm{STSI} \\
& \because Y=80 \mathrm{~m}, \mathrm{GF} \quad \longrightarrow Y=80 \mathrm{~m}, \mathrm{STSI}
\end{aligned}
$$

FIgURE 18: Comparison of longitudinal settlements between free-field and superstructure-included cases for the 6-story structure.

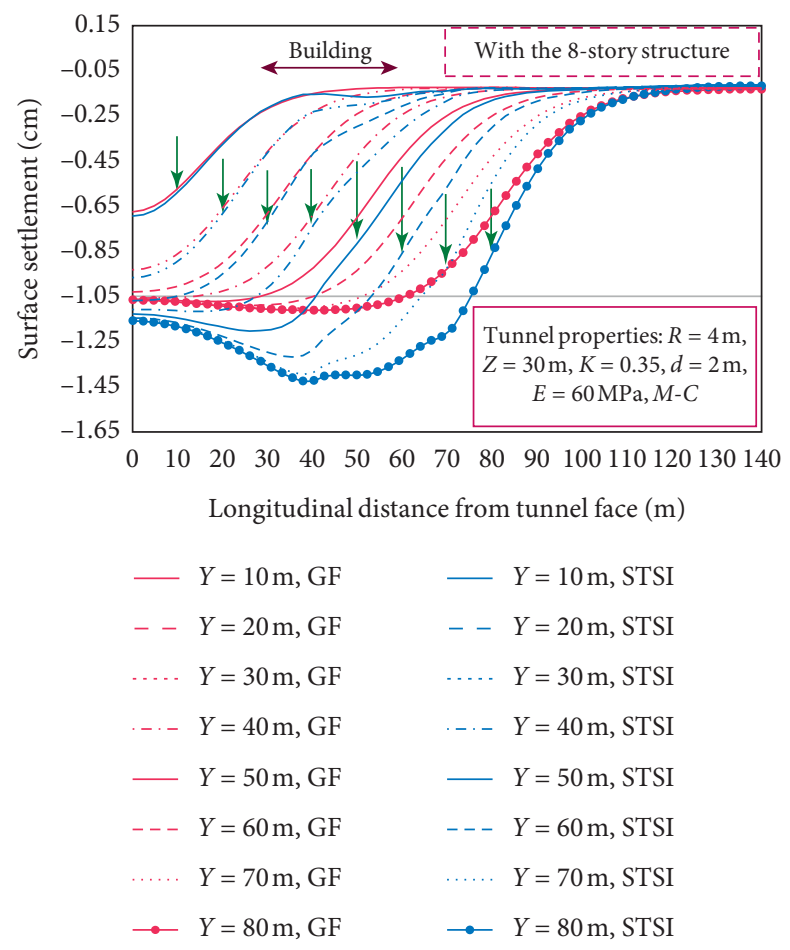

Figure 19: Comparison of longitudinal settlements between free-field and superstructure-included cases for the 8-story structure. 


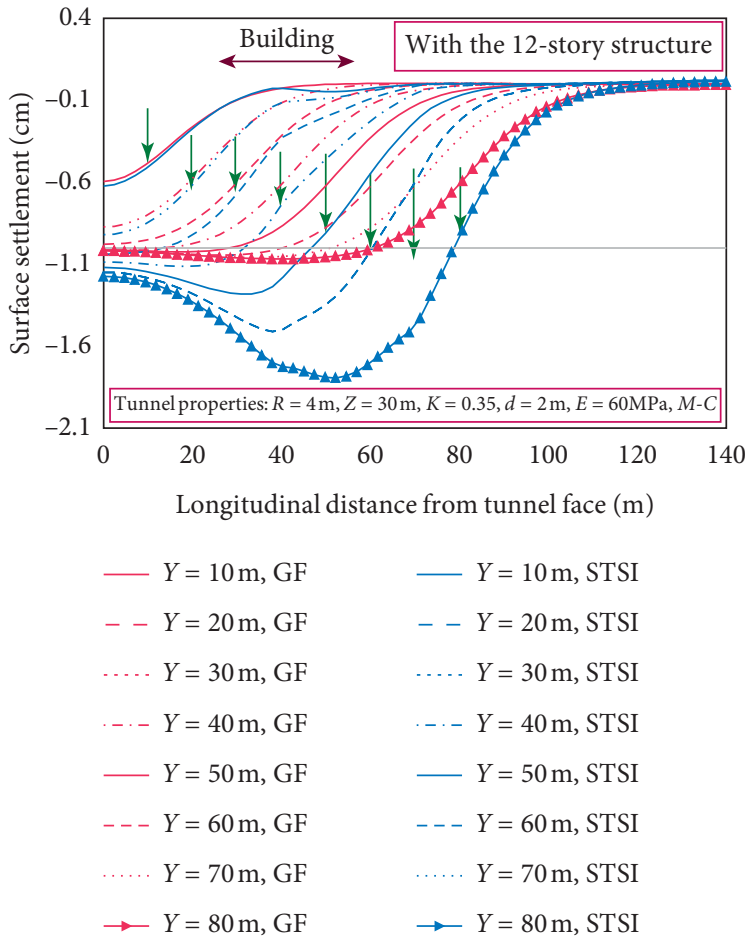

Figure 20: Comparison of longitudinal settlements between free-field and superstructure-included cases for the 12-story structure.

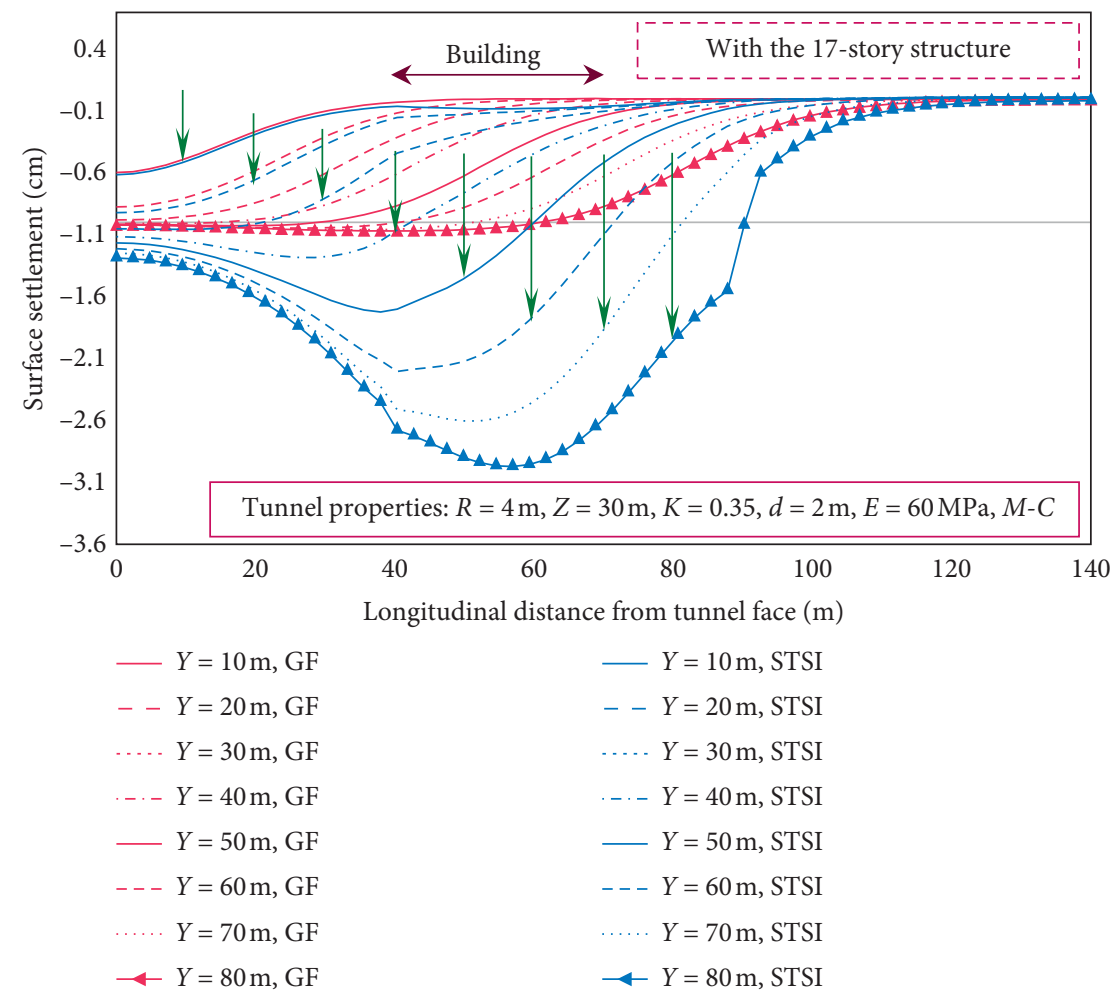

Figure 21: Comparison of longitudinal settlements between free-field and superstructure-included cases for the 17-story structure. 


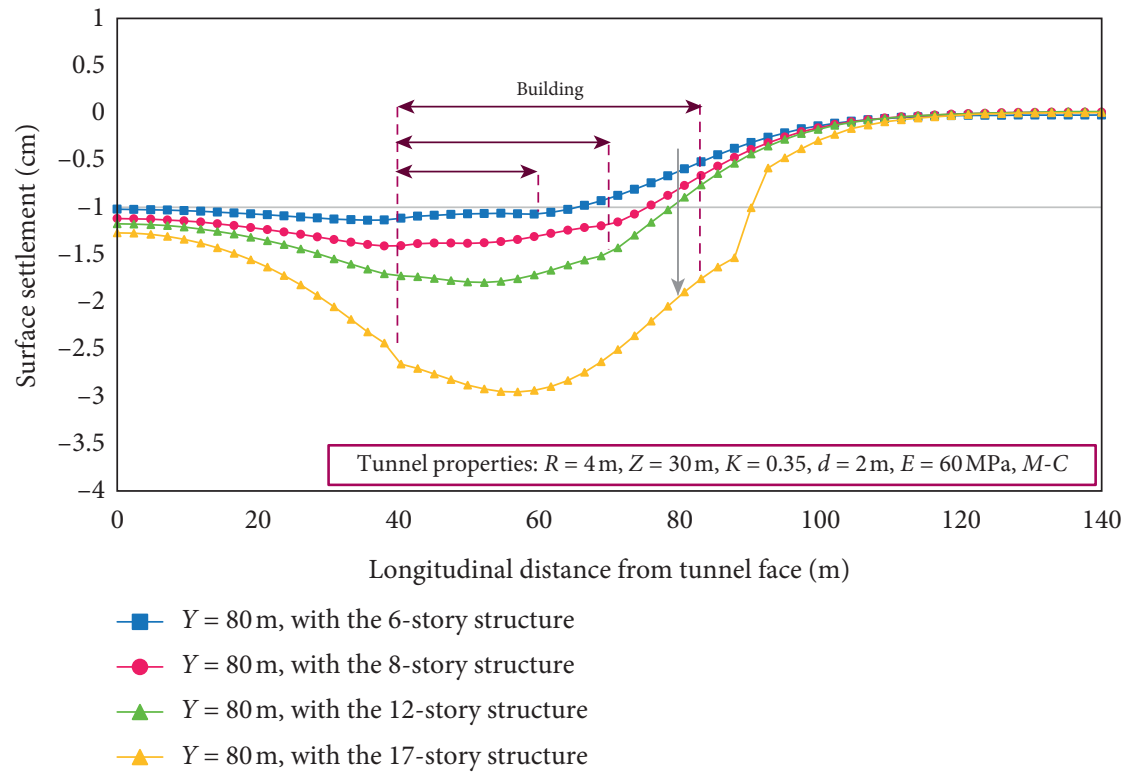

FIGURE 22: Comparison of the longitudinal tunneling-induced settlement profiles under the structure for different numbers of stories of the superstructure.

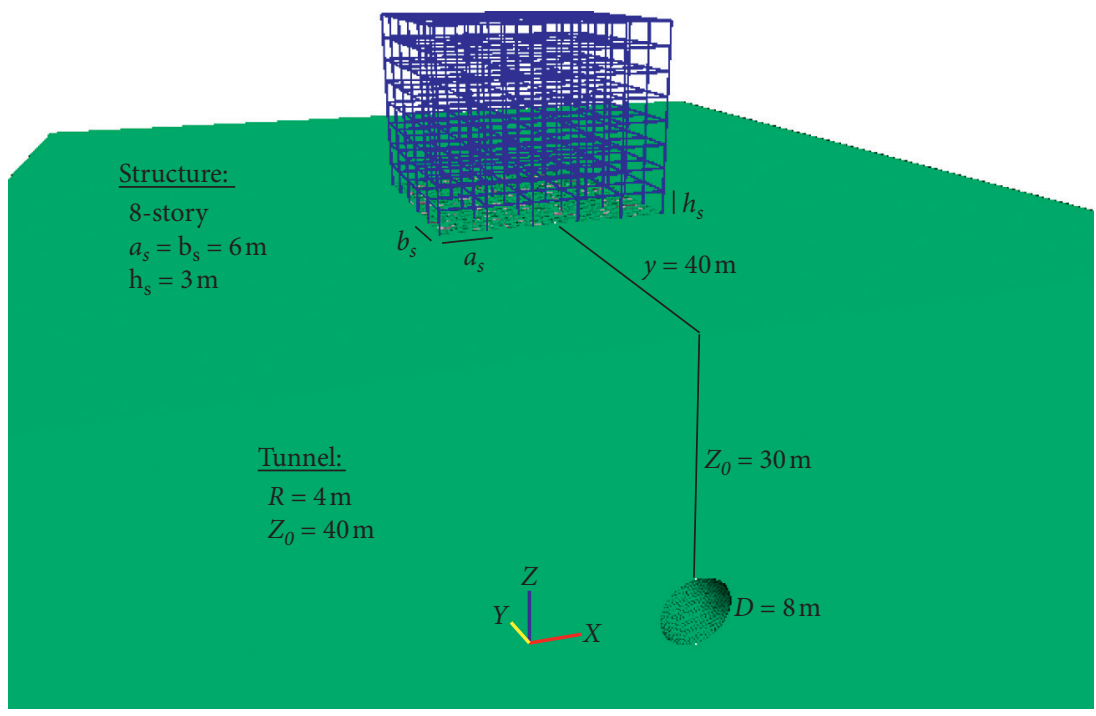

(a)

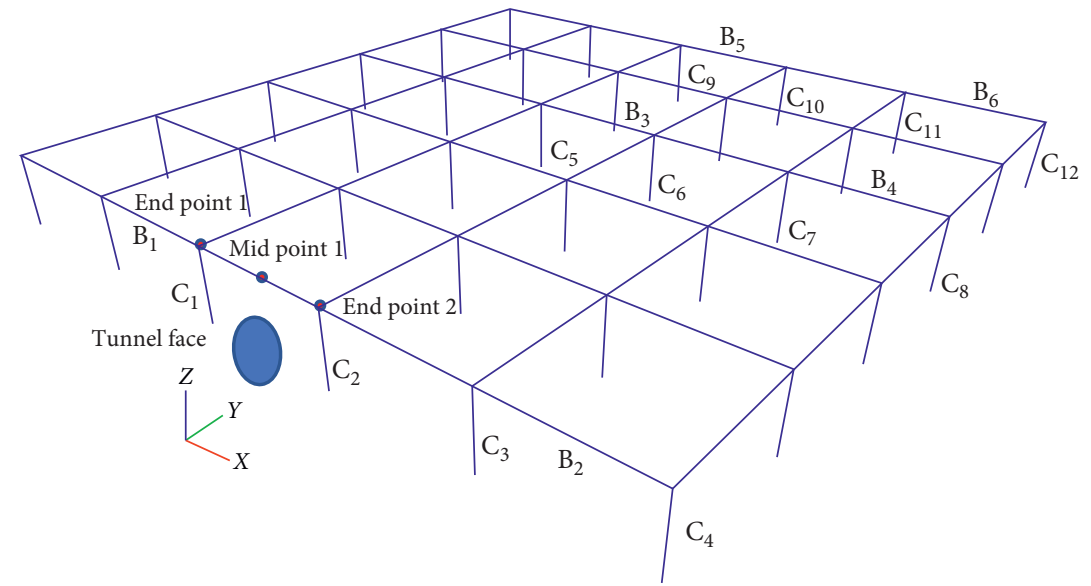

(b)

Figure 23: (a) Geometry of the tunnel and the superstructure. (b) Location of the studied beams and columns on the ground floor of the superstructure. 


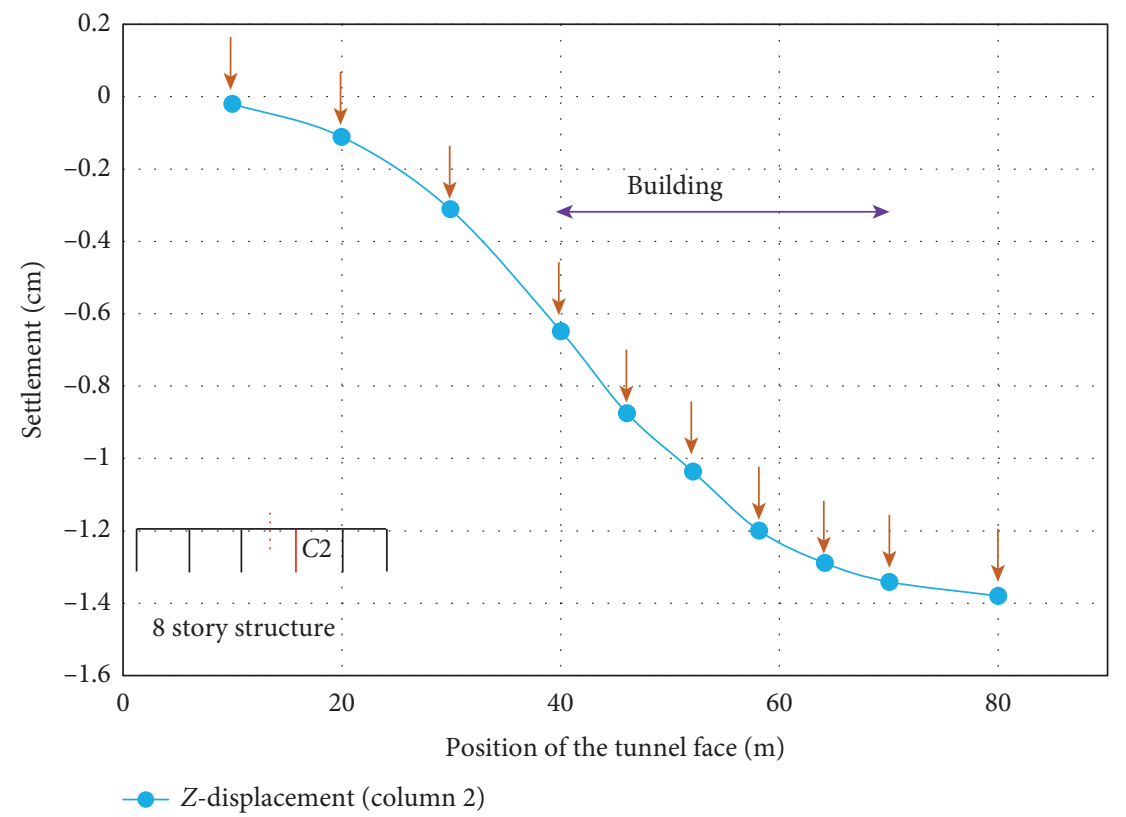

Figure 24: Variation of the vertical displacement of column $C_{2}$ versus the tunnel advancement.

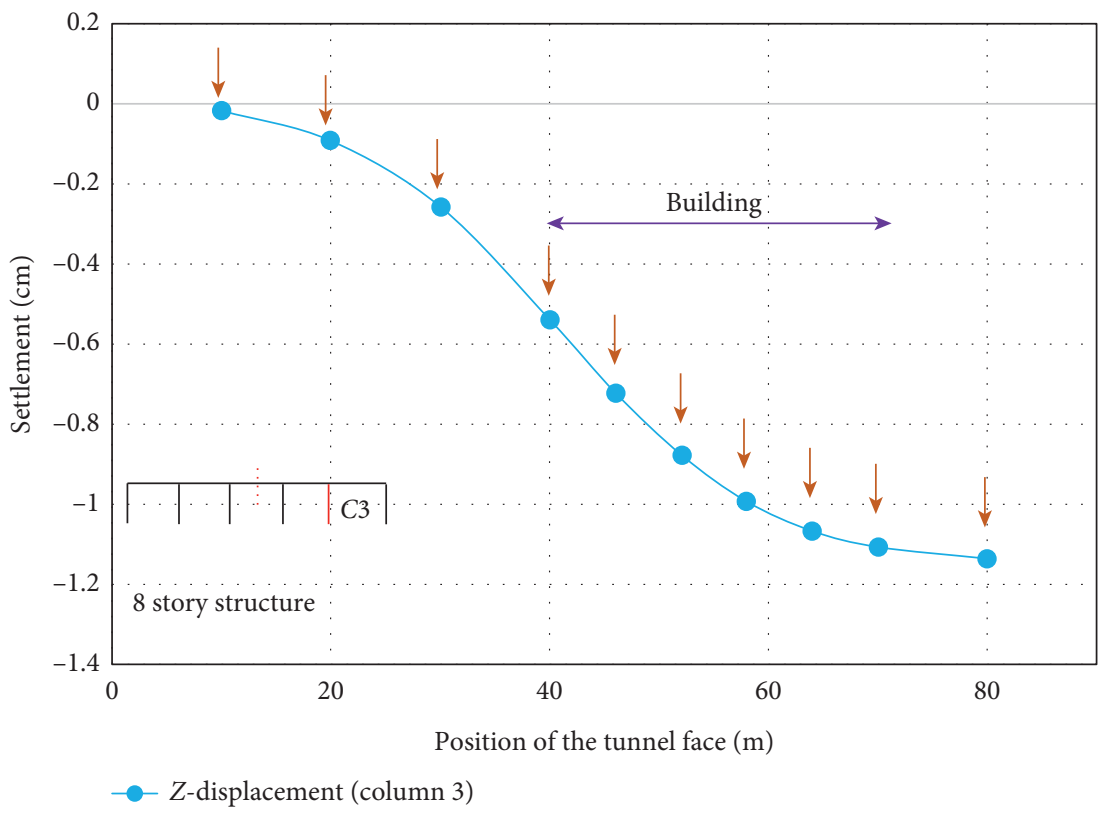

FIgURE 25: Variation of the vertical displacement of column $C_{3}$ versus the tunnel advancement. 


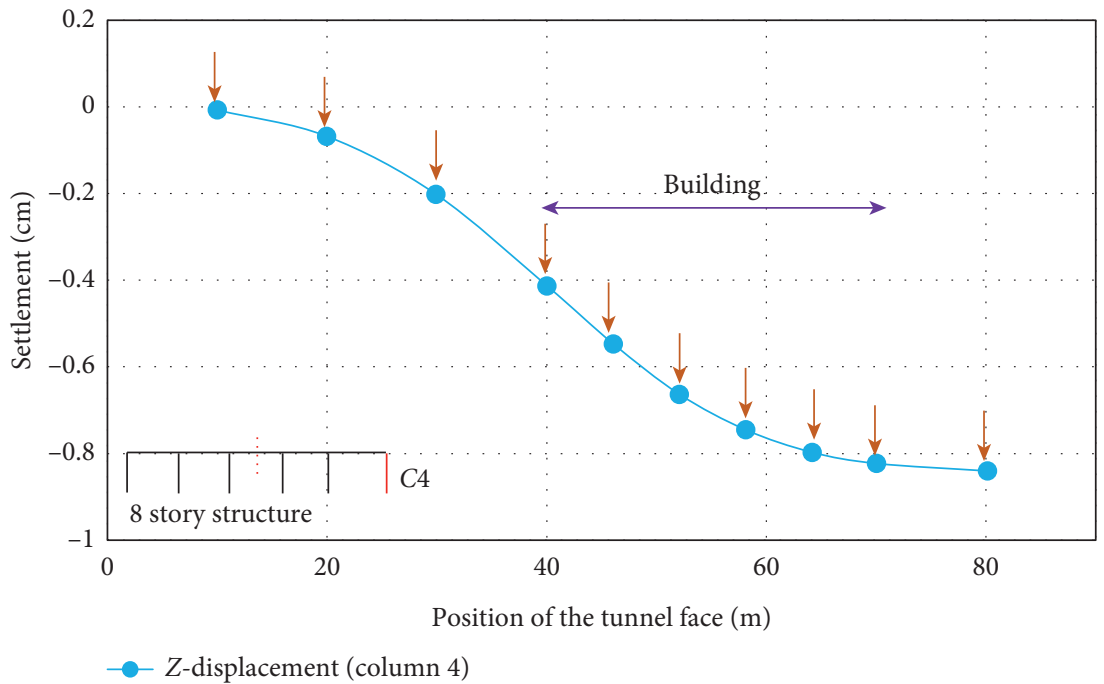

Figure 26: Variation of the vertical displacement of column $C_{4}$ versus the tunnel advancement.

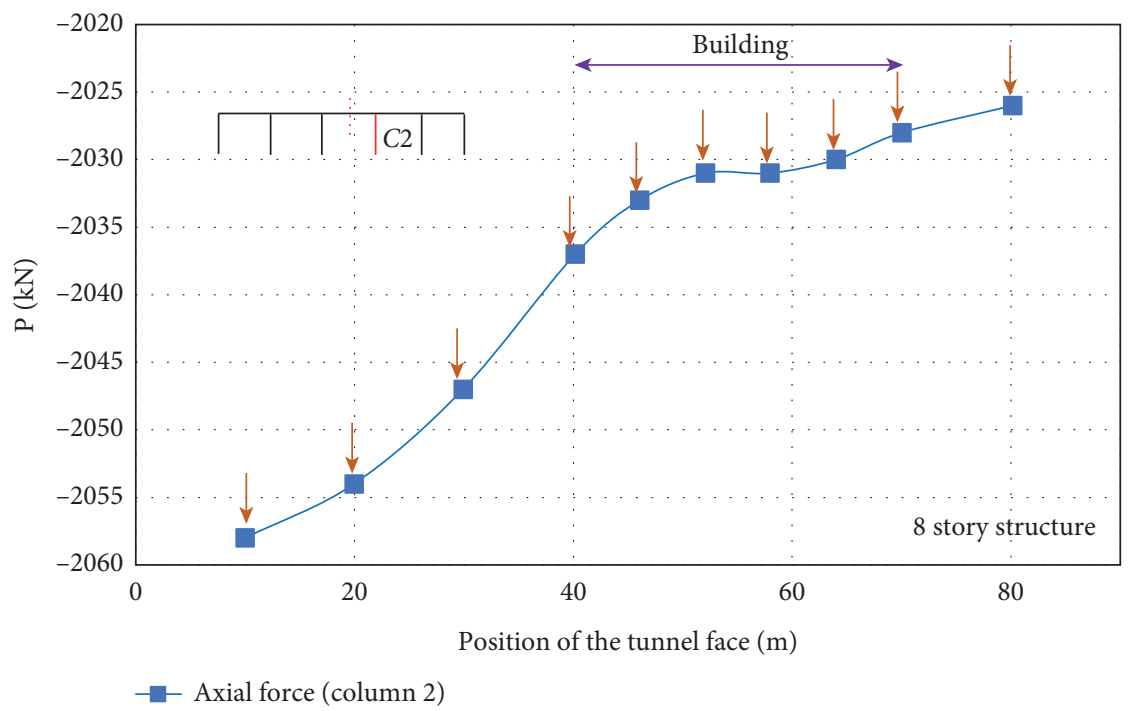

FIgURE 27: Variation of the axial force of column $C_{2}$ versus the tunnel advancement.

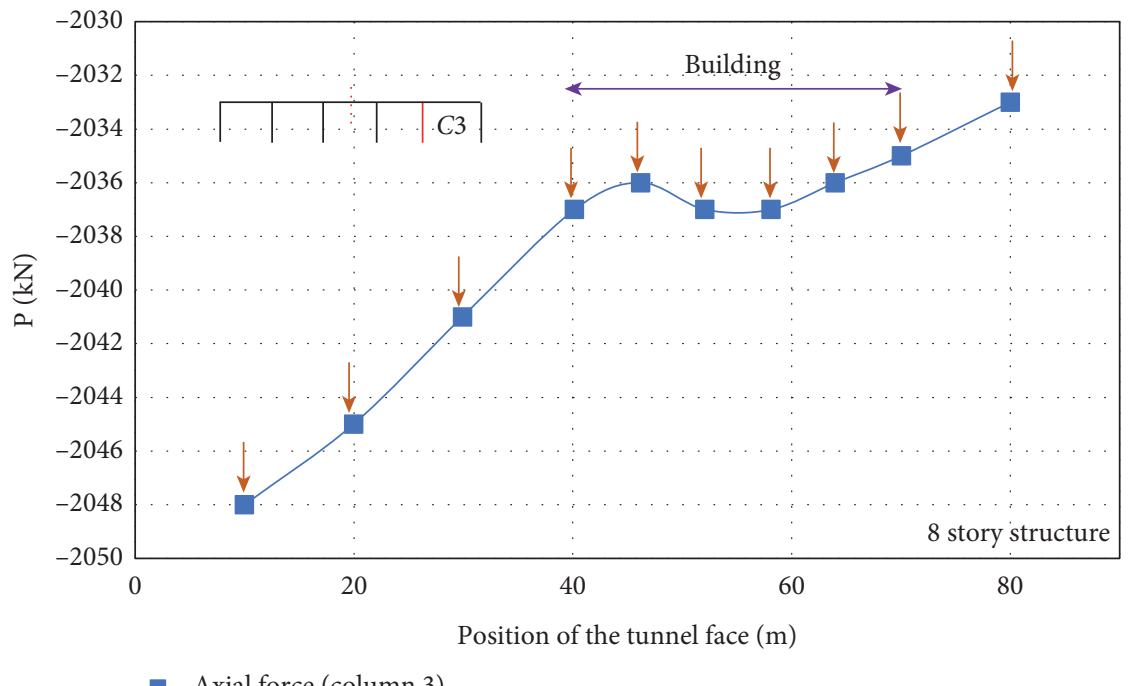

Figure 28: Variation of the axial force of column $C_{3}$ versus the tunnel advancement. 


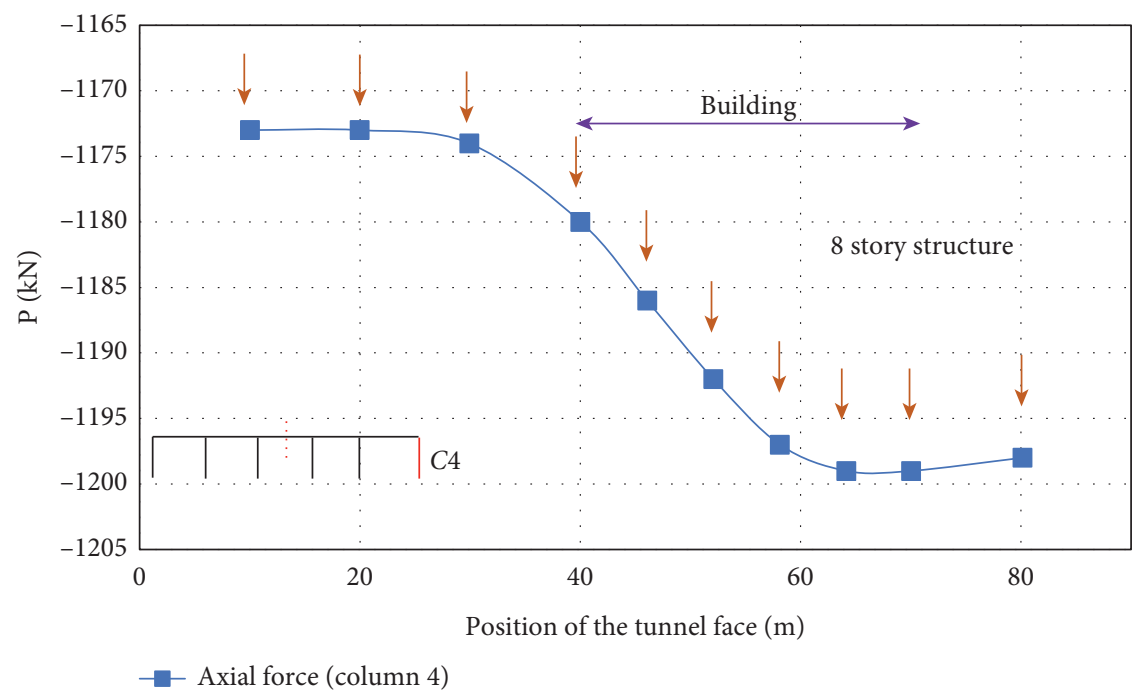

FIgURe 29: Variation of the axial force of column $C_{4}$ versus the tunnel advancement.

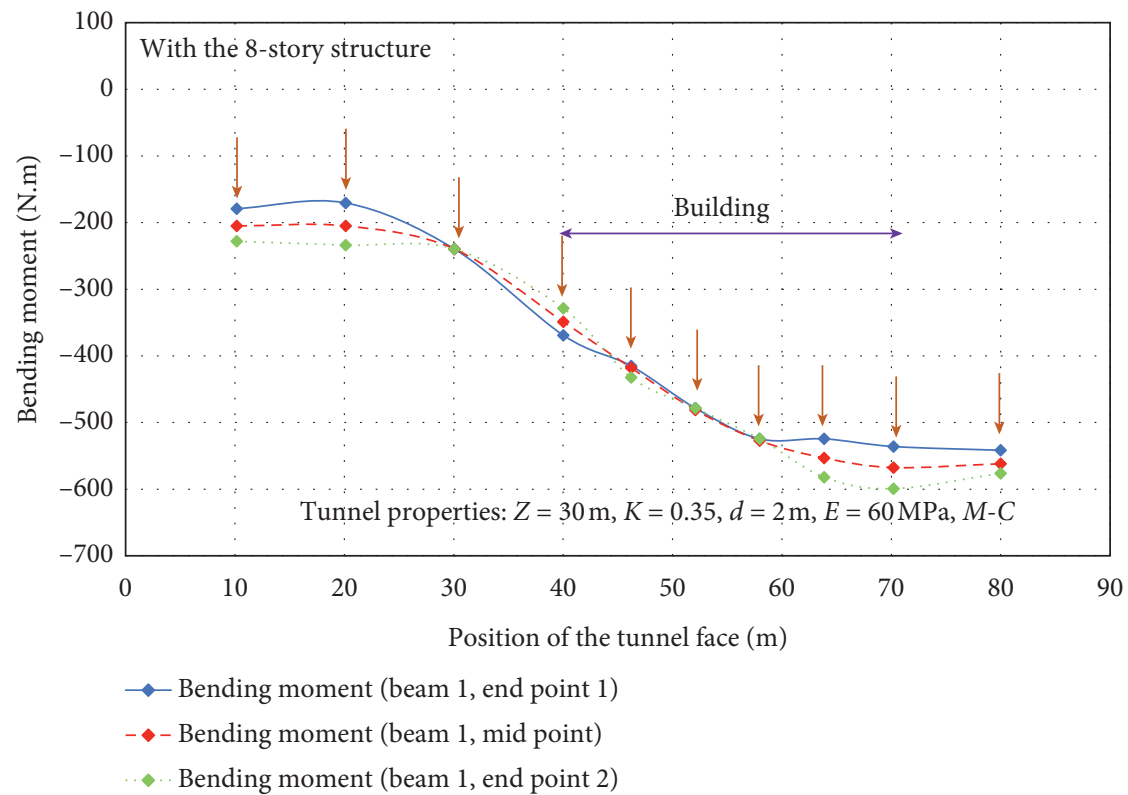

FIgURE 30: Variation of the bending moment of beam $B_{1}$ with the tunnel advancement.

\section{Conclusion}

In this paper, the ground-tunnel-superstructure interaction problem is studied based on the three-dimensional finite difference modeling and using Flac 3D software. To investigate effects of the sequential tunneling, the excavation of the whole section in the tunnel face is done in a single step, while the tunnel advancement is carried out in a stepwise, sequential manner. Also, the installation of concrete support is done with a delay step toward the progress of the tunnel. The developed numerical model is first validated against available two-dimensional and three-dimensional, analytical, and numerical models. Then, the well-validated numerical approach is adopted for conducting parametric studies on the effects of different parameters. It should be noted that, considering the meaningful impact of the proper selection of the material constitutive law and the model size on the shape and the values of the longitudinal settlement profile, an intensive sensitivity analysis is conducted prior to the final analyses. Based on the sensitivity of the longitudinal, tunneling-induced settlement profiles to different selected sizes and behaviors, proper model size and constitutive law are adopted. As another contribution of the present paper, effects of the diameter and the depth of the tunnel and also the number of the stories of the superstructure on the tunnelinginduced longitudinal ground settlements are investigated. Excess internal forces and moments caused in the elements of the structure because of the tunnel advancement are also 
evaluated and further discussed. Based on the results obtained, the following can be concluded:

(i) For the free-field case, with advancing the tunnel face, longitudinal settlement profiles tend to a steady state, and steady state means that, in the longitudinal profiles, the vertical settlement will no longer exceed a maximum value.

(ii) Models with the superstructure behave differently; superstructure causes a considerable change in both figures and values of the longitudinal settlement profiles. Settlements increase as the tunnel face advances until the facing passes through the location of the superstructure. With advancing the facing toward the location of the structure, differences between free-field settlements and the superstructure's case increase. Maximum difference corresponds to the midpoint of the superstructure; in this state, the superstructure experiences an unbalanced settlement with respect to the tunnel face. After that, with passing the tunnel face through the location of the superstructure, this unbalanced settlement decreases. Maximum occurring settlement refers to the state that the tunnel face completely passes through the superstructure. In addition, despite the case of free-field settlements, there is not a steady-state condition prior to passing through the structure.

(iii) With increasing the diameter of the tunnel, tunneling-induced settlements significantly increase. In other words, the increased diameter of the tunnel enhances the effect of the superstructure on the settlements. This is the main reason why there is a higher difference between the settlements of the free-field and superstructure included cases. Increasing the tunnel diameter increases both maximum ground settlement and the value of the settlement at the tunnel opening (at the beginning of the model).

(iv) With increasing the depth of tunneling, values of the settlement increase; however, effects of the interaction between tunnel excavation and the superstructure decrease. For example, when a tunnel is excavated at a depth of 15 meters under an 8-story structure, the maximum settlement on the ground increases by more than $130 \%$ compared to the free-field condition, but when the tunnel is at a depth of 45 meters under an 8-story structure, only a $15 \%$ increase in settlement occurs.

(v) In creasing the depth of the tunneling increases both maximum ground settlement and the value of the settlement at the tunnel opening.

(vi) When the tunnel face completely passes through the superstructure, the longitudinal settlement profile of the 6-story building shows a slight heaving behavior, which can be attributed to the low number of stories and, hence, the enhanced stiffness of the superstructure. In such a condition, the settlement profile is quite identical to the free-field graph. With increasing the number of stories and the weight of the structure, maximum settlement of the ground significantly increases and the heaving behavior under the structure (shown for the low-story buildings) decreases. For example, when the number of stories increases to 8 , the maximum settlement relative to the ground without a surface structure increases by $40 \%$, and when the surface structure is 12 stories, it is about $70 \%$. For structures with more than 17 stories, there is a considerable difference between the settlement profiles of free-field and superstructure-soil interaction cases.

(vii) It is observed that the effect of number of stories of the superstructure on the maximum settlement is more noticeable compared to its impact on the settlement value at the opening of the tunnel.

(viii) The most important impact of the tunnel excavation on the superstructure is redistribution of the internal, structural forces and moments in the beams and columns. Due to the ground settlement and the vertical displacements observed in the beams/columns, the stress release occurs, and the axial force of the columns decreases or increases. The closer the column is to the tunnel axis, the greater its settlement, and the steeper the column settlement curve as the tunnel face passes under the structure. Due to the subsidence of the columns adjacent to the axis of the tunnel, their axial force increases, but the axial force of the columns farther from the axis of the tunnel increases due to the redistribution of force between the columns, even if they are settled. For example, numerical analysis performed in this paper showed that the passage of a tunnel with a diameter of 8 meters under an 8story building and at a depth of $30 \mathrm{~m}$ causes the column located at a distance of $3 \mathrm{~m}$ from the axis of the tunnel $\left(C_{2}\right)$ to settle $1.4 \mathrm{~cm}$ and its axial force is reduced by $31 \mathrm{kN}$, and the column, located $9 \mathrm{~m}$ from the axis of the tunnel $\left(C_{3}\right)$, settles $1.1 \mathrm{~cm}$ and its axial force is reduced by $14 \mathrm{kN}$ and column located $15 \mathrm{~m}$ from the axis of the tunnel $\left(C_{4}\right)$ will settle $0.82 \mathrm{~cm}$, but its axial force will increase by $25 \mathrm{kN}$.

\section{Data Availability}

No data were used to support this study.

\section{Conflicts of Interest}

The authors declare that they have no conflicts of interest.

\section{References}

[1] R. B. Peck, "Deep excavations and tunneling in soft ground," in Proceeding of the 7th International Conference.SMFE, State of the Art, pp. 225-290, Mexico, MX, USA, July 1969. 
[2] M. O'reilly and B. New, Settlements above Tunnels in the United Kingdom-their Magnitude and Prediction, Institution of Mining \& Metallurg, London, UK, 1982.

[3] N. Loganathan and H. G. Poulos, "Analytical prediction for tunneling-induced ground movements in clays," Journal of Geotechnical and Geoenvironmental Engineering, vol. 124, no. 9, pp. 846-856, 1998.

[4] P. Vermeer, P. Bonnier, and S. Möller, "On a smart use of 3DFEM in tunnelling," in Proceeding of Eighth International Symposium on Numerical Models in Geomechanics, pp. 361366, Rome, Italy, April 2002.

[5] S. C. Möller, Tunnel Induced Settlements and Structural Forces in Linings, University. Stuttgart Institute of Geotechnik, Stuttgart, Germany, 2006.

[6] A. Ghorbani and H. Hasanzadehshooiili, "A comprehensive solution for the calculation of ground reaction curve in the crown and sidewalls of circular tunnels in the elastic-plasticEDZ rock mass considering strain softening," Tunnelling and Underground Space Technology, vol. 84, pp. 413-431, 2019.

[7] R. Katzenbach, S. Leppla, M. Vogler, M. Seip, and S. Kurze, "Soil-structure-interaction of tunnels and superstructures during construction and service time," Procedia Engineering, vol. 57, pp. 35-44, 2013.

[8] G. Giardina, M. J. DeJong, and R. J. Mair, "Interaction between surface structures and tunnelling in sand: centrifuge and computational modelling," Tunnelling and Underground Space Technology, vol. 50, pp. 465-478, 2015.

[9] A. H. Akhaveissy, "Analysis of tunnel and super structures for excavation," Scientia Iranica, vol. 18, no. 1, pp. 1-8, 2011.

[10] A. Mirhabibi and A. Soroush, "Three-dimensional simulation of interaction between surface buildings and twin tunnelling regarding the surface settlement," Geotechnical Geological Engineering, vol. 38, pp. 5143-5166, 2020.

[11] H. Mroueh and I. Shahrour, "A full 3-D finite element analysis of tunneling-adjacent structures interaction," Computers and Geotechnics, vol. 30, no. 3, pp. 245-253, 2003.

[12] C. Wroth and J. Burland, "Settlement of buildings and associated damage," in SOA Review, Conf. Settlement of StructuresPentech Press, Cambridge, UK, 1974.

[13] R. Mair, "Prediction of ground movements and assessment of risk of building damage due to bored tunnelling," in Proceedings of the. Geotechnical Aspects of Underground Construction in Soft Ground, London, UK, April 1996.

[14] D. Potts and T. Addenbrooke, "A structure's influence on tunnelling-induced ground movements," in Proceedings of the Institution of Civil Engineers, Geotechnical Engineering, Muscat, Oman, April 1997.

[15] J. Franzius and T. Addenbrooke, "The influence of building weight on the relative stiffness method of predicting tunnelling-induced building deformation," in Proceedings of the Third International Symposium (IS-Toulouse 2002) Geotechnical Aspects of Underground Construction in Soft Ground, pp. 53-57, Cambridge, UK, October 2002.

[16] C. Leung, J. Yu, Y. Chow, Y. Ng, H. Tan, and C. Hua, "Tunneling beneath existing buildings supported on shallow foundations," in Proceedings of the 4th Geo-China International Conference, pp. 251-258, Shandong, China, July 2016.

[17] H. Burd, G. Houlsby, C. Augarde, and G. Liu, "Prediction of tunnel-induced settlement damage to masonry Structures," OUEL Report 2162/98, Department of Engineering Science, Oxford, UK, 1998.

[18] J. Pickhaver, H. Burd, and G. Houlsby, "An equivalent beam method to model masonry buildings in $3 \mathrm{D}$ finite element analysis," Computers \& Structures, vol. 88, no. 19-20, pp. 1049-1063, 2010.

[19] D. Dias and R. Kastner, "Tunneling in soils-ground movements, and damage to buildings," in Proceedings of the Planning and Engineering for the Cities of Tomorrow. Second International Conference on Soil Structure Interaction in Urban Civil Engineering Swiss, Federal Institute of Science and Technology, Mookkannoor, India, January 2002.

[20] O. Jenck and D. Dias, Tunnelling on Urban Areas: 3D Numerical Analysis of Soil/structure Interaction, Is Amsterdam'05, Amsterdam, Netherland, 2006.

[21] M. Maleki, H. Sereshteh, M. Mousivand, and M. Bayat, "An equivalent beam model for the analysis of tunnel-building interaction," Tunnelling and Underground Space Technology, vol. 26, no. 4, pp. 524-533, 2011.

[22] J. N. Franzius, Behaviour of Buildings Due to Tunnel Induced Subsidence, University of London, London, UK, 2003.

[23] J. N. Franzius, D. M. Potts, and J. B. Burland, "The influence of soil anisotropy andK0on ground surface movements resulting from tunnel excavation," Géotechnique, vol. 55, no. 3, pp. 189-199, 2005.

[24] L. Chow, The Prediction of Surface Settlements Due to Tunnelling in Soft Ground, University of Oxford, Oxford, UK, 1994.

[25] G. Calabresi, S. Rampello, and L. Callisto, "Prediction of tunnel-induced displacements in historic buildings: the case of castel S.angelo," in Proceedings of the Twelf European Conference on Soil Mechanics and Geotechnical Engineering (Proceedings) The Netherlands Society of Soil Mechanics and Geotechnical Engineering, Ministry of Transport, Amsterdam, Netherlands, June 1999.

[26] P. Guedes and C. Santos Pereira, "The role of the soil $K_{0}$ value in numerical analysis of shallow tunnels," in Proceeding of the International Symposium on Geotechnical Aspects of Underground Construction in Soft Ground, CRC Press, Boca Raton,FL, USA, December 2000.

[27] V. Fargnoli, C. G. Gragnano, D. Boldini, and A. Amorosi, “3D numerical modelling of soil-structure interaction during EPB tunnelling," Géotechnique, vol. 65, no. 1, pp. 23-37, 2015.

[28] Itasca Consulting Group, Inc, FLAC3D - Fast Lagrangian Analysis of Continua in Three-Dimensions, Itasca, Minneapolis, MN, USA, 7.0 edition, 2019.

[29] E. Hoek, "Support for very weak rock associated with faults and shear zones," in Proceedings of the Rock Support and Reinforcement Practice in Mining, Routledge, Kalgoorlie,Australia, March 1999.

[30] S. Dragojević, "Analysis of ground settlement caused by tunnel construction," Građevinar, vol. 64, no. 7, pp. 573-581, 2012.

[31] M. Panet and A. Guento, "Analysis of convergence behind the face of a tunneli," in Proceeding of the International Symposium Tunneling, pp. 197-204, IMM, London, UK, June 1982.

[32] T. Unlu and H. Gercek, "Effect of Poisson's ratio on the normalized radial displacements occurring around the face of a circular tunnel," Tunnelling and Underground Space Technology, vol. 18, no. 5, pp. 547-553, 2003. 